\title{
Synergy of Direct and Indirect Cholinergic Septo- Hippocampal Pathways Coordinates Firing in Hippocampal Networks
}

\author{
일olger Dannenberg, ${ }^{1}$ Milan Pabst, ${ }^{1}$ Oliver Braganza, ${ }^{1}$ Susanne Schoch, ${ }^{2}$ 이ohannes Niediek, ${ }^{3}$ Melike Bayraktar, ${ }^{3}$ \\ Florian Mormann, ${ }^{3}$ and Heinz Beck ${ }^{1,4}$ \\ ${ }^{1}$ Laboratory for Experimental Epileptology and Cognition Research, Department of Epileptology, ${ }^{2}$ Section of Translational Epileptology, Institute for \\ Neuropathology, and ${ }^{3}$ Cognitive and Clinical Electrophysiology, Department of Epileptology, University of Bonn Medical Center, 53105 Bonn, Germany, \\ and ${ }^{4}$ Deutsches Zentrum für Neurodegenerative Erkrankungen, 53105 Bonn, Germany
}

The medial septum/diagonal band of Broca complex (MSDB) is a key structure that modulates hippocampal rhythmogenesis. Cholinergic neurons of the MSDB play a central role in generating and pacing theta-band oscillations in the hippocampal formation during exploration, novelty detection, and memory encoding. How precisely cholinergic neurons affect hippocampal network dynamics in vivo, however, has remained elusive. In this study, we show that stimulation of cholinergic MSDB neurons in urethane-anesthetized mice acts on hippocampal networks via two distinct pathways. A direct septo-hippocampal cholinergic projection causes increased firing of hippocampal inhibitory interneurons with concomitantly decreased firing of principal cells. In addition, cholinergic neurons recruit noncholinergic neurons within the MSDB. This indirect pathway is required for hippocampal theta synchronization. Activation of both pathways causes a reduction in pyramidal neuron firing and a more precise coupling to the theta oscillatory phase. These two anatomically and functionally distinct pathways are likely relevant for cholinergic control of encoding versus retrieval modes in the hippocampus.

Key words: acetylcholine; encoding; hippocampus; in vivo electrophysiology; medial septum; theta oscillation

\section{Introduction}

Neuromodulators such as acetylcholine (ACh) are of central importance in modulating cortical rhythmogenesis and behavior. In the hippocampus, ACh is mainly derived from cholinergic neurons in the medial septum/diagonal band of Broca complex (MSDB) (Mesulam et al., 1983). In this structure, ACh is thought to promote functional network states that allow efficient encoding of novel information. In hippocampal networks, this is achieved by increasing theta activity and synchronization of neurons within and across regions, thus promoting synaptic plasticity (Pavlides et al., 1988; Hyman et al., 2003). At the same time, ACh inhibits recurrent CA3 networks relevant for information retrieval. For example, synaptic transmission from longitudinal association fibers is cholinergically suppressed in vitro (Hasselmo et al., 1995) and ACh release in the

\footnotetext{
Received Oct. 28, 2014; revised April 2, 2015; accepted April 5, 2015.

Author contributions: H.D. and H.B. designed research; H.D., M.P., and 0.B. performed research; S.S., J.N., M.B., and F.M. contributed unpublished reagents/analytic tools; H.D. analyzed data; H.D. and H.B. wrote the paper.

This work was supported by the Deutsche Forschungsgemeinschaft (DFG Grant SFB 1089 to H.B., S.S., and F.M.i DFG German-French binational program grant to H.B.), the Federal Ministry of Education and Research (BMBF Grant $01 G Q 0806$ to S.S.), and the ERANET Neuron EpiNet (H.B.). We thank Olivia van Ray and Margit Reitze for excellent technical assistance.

The authors declare no competing financial interests.

Correspondence should be addressed to Heinz Beck, Laboratory for Experimental Epileptology and Cognition Research, Department of Epileptology, University of Bonn Medical Center, Sigmund-Freud-Straße 25, D-53105 Bonn, Germany. E-mail: heinz.beck@ukb.uni-bonn.de.

DOI:10.1523/JNEUROSCI.4460-14.2015

Copyright $\odot 2015$ the authors $\quad 0270-6474 / 15 / 358394-17 \$ 15.00 / 0$
}

hippocampus suppresses sharp-wave ripple events in the CA3 region in vivo (Vandecasteele et al., 2014).

Consistent with this notion, both hippocampal ACh release and hippocampal theta activity are increased during exploration or novelty experience, as well as during arousal or stress (Giovannini et al., 2001; Anzalone et al., 2009; Stanley et al., 2012; for reviews see Bland, 1986; Stewart and Fox, 1990; Buzsáki, 2002; Buzsáki and Moser, 2013). Conversely, lesions of cholinergic MSDB neurons or the septo-hippocampal pathway impair recognition of novel place (Cai et al., 2012) and spatial learning (Berger-Sweeney et al., 2001; Moreau et al., 2008). Moreover, pharmacologically blocking ACh receptors locally in the hippocampal CA 3 or CA1 regions disrupts encoding of spatial information while sparing retrieval (Rogers and Kesner, 2003).

The presence of rhythmically bursting cells in the MSDB, initially discovered in rabbits (Petsche et al., 1962; Stumpf et al., 1962), gave rise to the hypothesis that the MSDB serves as a "pacemaker" for the hippocampal theta rhythm. Indeed, lowerfrequency theta oscillations $(3-6 \mathrm{~Hz})$ during alert immobility and under urethane anesthesia are fully abolished by muscarinic blocker injection into the MSDB (Kramis et al., 1975). However, freely moving animals show a faster theta component that is only partly inhibited by cholinergic blockers (Kramis et al., 1975) or selective lesions of cholinergic MSDB neurons (Lee et al., 1994; Bassant et al., 1995).

When more extensive lesions of either the MSDB or the fimbriafornix pathway were performed in urethane-anesthetized animals (Andersen et al., 1979) or awake animals (Green and Arduini, 
1954; Donovick, 1968; Rawlins et al., 1979), hippocampal theta rhythms were completely abolished. Likewise, global inhibition of MSDB activity in freely moving animals eliminates theta oscillations (Chrobak et al., 1989; Lawson and Bland, 1993; Givens and Olton, 1994). Moreover, combined lesions of both GABAergic and cholinergic neurons abolish theta oscillations, whereas lesioning either system individually causes an incomplete reduction (Yoder and Pang, 2005).

These data suggest that neurons of the MSDB drive hippocampal theta oscillations and that different MSDB systems cooperate to achieve hippocampal modulation. Furthermore, they establish the relevance of the septo-hippocampal system for inducing a hippocampal state that allows the detection of novelty and formation of new memories. How precisely cholinergic neurons affect hippocampal network dynamics in vivo, however, has remained elusive. We show here that cholinergic MSDB neurons generate hippocampal theta rhythm via an MSDB relay. Simultaneously, hippocampal inhibitory interneuron activity is increased, whereas principal cell activity is decreased via direct septo-hippocampal projections. This results in an increased spike-phase coupling of hippocampal principal neurons.

\section{Materials and Methods}

Mice. For optogenetic stimulation experiments, adult homozygous

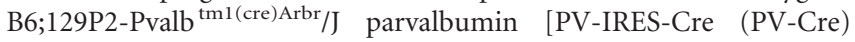
knock-in mice; The Jackson Laboratory] or heterozygous B6;129S6-

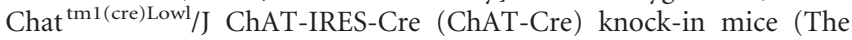
Jackson Laboratory) of both sexes were used. Mice were bred under pathogen-free conditions in an animal facility and maintained on a $12 \mathrm{~h}$ light/dark cycle with rodent chow and water ad libitum in groups of two to four animals per cage. Male mice were separated and housed as singles after surgery. All animal experiments were conducted in accordance with the guidelines of the Animal Care and Use Committee of the University of Bonn.

Viral transduction. We used a recombinant adenoassociated virus (rAAV) of the serotype 2 genome contained in a hybrid serotype 1 and 2 capsid (S2/1) carrying the humanized channelrhodopsin 2 with the H134R mutation (hChR2) (Nagel et al., 2005) fused to the enhanced yellow fluorescent protein (eYFP) in a double-floxed inverted open reading frame under control of the human elongation factor- $1 \alpha$ promoter. This rAAV was injected under stereotactic control into the MSDB of ChAT-Cre and PV-Cre mice to achieve specific expression of hChR2eYFP in cholinergic and GABAergic neurons, respectively. The plasmid (Addgene plasmid 20298) was provided by Karl Deisseroth (Stanford University). For a detailed description of the virus production, see van Loo et al. (2012). For virus injection, mice within an age of 6-10 weeks were anesthetized via an intraperitoneal injection of ketamine (100 $\mathrm{mg} / \mathrm{kg}$ body weight, WDT, Garbsen, Germany) and medetomidine (1 $\mathrm{mg} / \mathrm{kg}$ body weight, Domitor; Orion Pharma). Both drugs were diluted in sterile $0.9 \%$ sodium chloride solution (Fresenius Kabi) to inject a volume of $100 \mu \mathrm{l}$ per $10 \mathrm{~g}$ body weight. During surgery, mice were kept on a $37^{\circ} \mathrm{C}$ heating table and eye ointment (Bepanthen; Bayer) was used to prevent corneal drying. Local anesthesia ( $10 \%$ lidocaine, xylocain pumpspray; AstraZeneca) was applied to the skin above the skull before making an incision to expose the skull surface. After scraping away the pericranium, a burr hole was made at a stereotactically identified site above the MSDB ( $1 \mathrm{~mm}$ anterior to bregma, $0.7 \mathrm{~mm}$ lateral-right to the midline). Injection was aimed at 2 sites at 4.8 and $4.4 \mathrm{~mm}$ ventral to bregma with a $10^{\circ}$ polar and $-90^{\circ}$ azimuth angle. The stereotactic coordinates were obtained from the atlas of Paxinos and Franklin (2008). A total amount of $2 \mu \mathrm{l}$ viral suspension was injected via a microcontroller (SYS-MICRO4; WPI) operated electrical micropump (UMP3; WPI) at a rate of $100 \mathrm{nl} / \mathrm{min}$ through a $34 \mathrm{~g}$ bevelled needle (NanoFil; WPI) at the two ventral sites ( $1 \mu \mathrm{l}$ at each site). The needle was kept in place for 3 min after injection at the first position and for $5 \mathrm{~min}$ after injection at the second position before withdrawal to prevent backflow of the virus. A broadband antibiotic ointment (Polyspectran; Alcon Pharma) was applied to the wound and the skin was sutured using an absorbable antibacterial thread (Coated VICRYLR Plus antibacterial polyglactin 910 5-0 RB10.70 suture; Johnson \& Johnson Medical). Buprenorphine hydrochloride $(50 \mu \mathrm{g} / \mathrm{kg}$ body weight, B9275; Sigma-Aldrich) for analgesia and atipamezole $(5 \mathrm{mg} / \mathrm{kg}$ body weight, Antisedan; Orion Pharma) for antagonizing medetomidine were injected intraperitoneally after surgery. Both drugs were diluted in sterile $0.9 \%$ sodium chloride solution to inject a volume of 50 and $100 \mu \mathrm{l}$ per $10 \mathrm{~g}$ bodyweight (buprenorphine and medetomidine, respectively). Mice were housed for at least 3 weeks before performing electrophysiological experiments to give them time to recover and to give $\mathrm{ChR} 2$ time to accumulate in the cell membrane.

In vivo electrophysiological recordings. For electrophysiological experiments, mice were anesthetized with two intraperitoneal injections of urethane (catalog no. U2500; Sigma-Aldrich) separated by 30-45 min. The first injection was performed at a concentration of $1.5 \mathrm{~g} / \mathrm{kg}$ body weight, the second at $0.375 \mathrm{~g} / \mathrm{kg}$ body weight. The mouse head was fixed in a stereotactic frame (Model 900; David Kopf Instruments) while mice were kept on a heating plate to keep their body temperature stable between $36^{\circ} \mathrm{C}$ and $37^{\circ} \mathrm{C}$ throughout the experiment. Body temperature was monitored using a rectal probe. Two hundred microliters of Glucosteril $5 \%$ (Fresenius Kabi) were administered subcutaneously every $2 \mathrm{~h}$ throughout the experiment. The end of a bare light fiber ( 0.22 numerical aperture, $550 \mu \mathrm{m}$ core, BFL22-550; Thorlabs) was implanted with the front aperture just above the MSDB. The fiber tip was advanced $4 \mathrm{~mm}$ of radial distance away from the skull surface with a $10^{\circ}$ polar and $-90^{\circ}$ azimuth angle. At the skull surface, the penetration point of the fiber was adjusted to $1 \mathrm{~mm}$ anterior to bregma and $0.7 \mathrm{~mm}$ lateral-right to the midline. A $1.2 \mathrm{~mm}$ major diameter screw (00-96x1/16 mouse screw; Plastics One) was implanted above the cerebellum as a reference electrode. For experiments with focal injections into the MSDB, an additional hole was drilled $1.6 \mathrm{~mm}$ anterior to bregma and $0.6 \mathrm{~mm}$ lateral-right to the midline for insertion of an injection needle (34 g beveled NanoFil; WPI). The needle was advanced $4.1 \mathrm{~mm}$ of radial distance away from the ventral coordinate of bregma at a $10^{\circ}$ polar and $45^{\circ}$ azimuth angle. This resulted in the needle tip finally positioned at $1 \mathrm{~mm}$ anterior and $4.0 \mathrm{~mm}$ ventral to bregma exactly at the midline. For experiments with focal injections into the hippocampus, a hole was drilled $0.1 \mathrm{~mm}$ posterior to bregma and $2.7 \mathrm{~mm}$ lateral-right to the midline. The needle was advanced $2.7 \mathrm{~mm}$ from the ventral coordinate of bregma at a $45^{\circ}$ polar and $55^{\circ}$ azimuth angle. This resulted in the tip finally being positioned at $1.5 \mathrm{~mm}$ posterior, $1.6 \mathrm{~mm}$ right-lateral, and $1.9 \mathrm{~mm}$ ventral to bregma. For insertion of the silicon probe, a cranial window was drilled $1.7 \mathrm{~mm}$ posterior to bregma and 1.0-2.2 $\mathrm{mm}$ lateral-right to the midline above the dorsal hippocampus. The dura mater was removed and the silicon probe was advanced vertically with the tip at a depth of $2.2 \mathrm{~mm}$ from the cortical surface. The closest distance from the tip of the injection needle to the silicon probe shanks was $\sim 0.2 \mathrm{~mm}$.

The heart rate was monitored and recorded using a steel needle in the skin of the forepaw or hindpaw. In experiments with focal drug application, the microsyringe needle for focal drug injections was carefully advanced in a stepwise manner to the final position just above the MSDB using a microcontroller. Hippocampal field potentials were recorded simultaneously, allowing us to monitor whether the needle insertion itself affected the effects of medial septal optogenetic stimulation. This was never the case if the final location of the needle tip was above the MSDB as described. We did, however, observe strong effects of microinjection needle insertion if it was advanced further into the MSDB (data not shown).

Data acquisition. The silicon probe (A4x8-5 mm-100-400-413-A32; NeuroNexus) used for in vivo recordings of LFP and single unit activity had 32 electrode contacts, each with a surface area of $413 \mu \mathrm{m}^{2}$, distributed on four $15 \mu \mathrm{m}$ thick shanks, with each shank having eight electrodes vertically distributed with $100 \mu \mathrm{m}$ spacing. The distance between shanks was $400 \mu \mathrm{m}$. Intrahippocampal LFP signals were amplified $(100 \times)$ and acquired continuously at $48 \mathrm{kHz}$ on a 32-channel recording system with 16-bit resolution (dacqUSB; Axona). For determination of the electrode positions, a microspatula tip of a high molecular weight (500,000 MW) lysine-fixable biotinylated dextran conjugate (catalog no. D-7142; Invit- 
rogen) was dissolved in deionized water and carefully applied to the silicon probe shanks with a small brush before surgery.

Reconstruction of electrode position. After surgery, the mouse was deeply anesthetized via an intraperitoneal injection of ketamine (100 $\mathrm{mg} / \mathrm{kg}$ body weight) and xylazine $(20 \mathrm{mg} / \mathrm{kg}$ body weight $)$ and heart perfusion was performed with $5 \mathrm{ml}$ of Ringer's solution (Fresenius Kabi) at a rate of $2 \mathrm{ml} / \mathrm{min}$ while the abdominal aorta was clamped. The brain was removed and stored for $4 \mathrm{~d}$ at $4^{\circ} \mathrm{C}$ in a fixation solution containing 4\% methanol-stabilized formalin (catalog no. F1635; Sigma-Aldrich), dissolved in PBS (PBS, catalog no. L 182-10; Biochrom). Fiftymicrometer-thick coronal slices were cut with a vibratome (VT1000S; Leica) in ice-cold PBS solution and subsequently stained with a streptavidin-conjugated green fluorescent dye (Alexa Fluor 488 streptavidin; Invitrogen) diluted 1:500. The track and tip position of the silicon probe shanks were identified and used for electrode position reconstruction, corrected for 5\% estimated tissue shrinkage. Data from electrodes for which position could not be determined unambiguously were excluded from further analysis.

Pharmacology. For systemic intraperitoneal injections of atropine, we used atropine sulfate monohydrate (catalog no. A0257; Sigma-Aldrich) at a concentration of $50 \mathrm{mg} / \mathrm{kg}$ body weight. Atropine sulfate monohydrate was dissolved in sterile $0.9 \%$ sodium chloride solution at $5 \mathrm{mg} / \mathrm{ml}$ to inject a volume of $100 \mu \mathrm{l}$ per $10 \mathrm{~g}$ body weight. For focal injections of atropine into the MSDB, we used atropine sulfate monohydrate at a concentration of $7.2 \mathrm{~mm}$, dissolved in artificial CSF (ACSF) consisting of the following (in mM): $\mathrm{NaCl}, 125 ; \mathrm{KCl}, 3.5 ; \mathrm{NaH}_{2} \mathrm{PO}_{4}, 1.25 ; \mathrm{NaHCO}_{3}, 26$; $\mathrm{CaCl}_{2}, 2 ; \mathrm{MgCl}_{2}, 2$; D-glucose, 15 (Sigma-Aldrich). A total volume of 300 $\mathrm{nl}$ was injected at a rate of $100 \mathrm{nl} / \mathrm{min}$ via a microcontroller-operated electrical micropump through a $34 \mathrm{~g}$ beveled needle (see "Viral transduction" section). Data for the condition post-MSDB injection were acquired between 20 and $60 \mathrm{~min}$ after the end of the injection procedure.

For focal injections into the hippocampus, we used a blocker mixture of atropine sulfate monohydrate $(7.2 \mathrm{~mm})$, mecamylamine hydrochloride (10 mM, catalog no. 2843; Tocris Bioscience), and methyllycaconitine citrate $(20 \mu \mathrm{M}$, catalog no. 1029; Tocris Bioscience) dissolved in ACSF. Because, compared with the more spatially confined MSDB, the hippocampus is a very large structure, we injected $10 \times 200 \mathrm{nl}$ at $100 \mathrm{nl} / \mathrm{min}$, amounting to a total volume of $2 \mu \mathrm{l}$ over a time course of $1 \mathrm{~h}$ to allow diffusion of blocker solution over the entire dorsal hippocampus. Data for the condition posthippocampal injection were acquired $10 \mathrm{~min}$ after the end of the injection procedure for up to $90 \mathrm{~min}$.

In vivo optical stimulation. For optical stimulation, a softwarecontrolled $473 \mathrm{~nm}$ diode laser (LuxX 473-80; Omicron-Laserage Laserprodukte) was coupled via a FC/PC connection to a multimode light fiber ( 0.22 numerical aperture, $550 \mu \mathrm{m}$ core, BFL22-550; Thorlabs). The laser power was adjusted before each experiment to yield a light power of $45 \mathrm{~mW}$ exiting the bare light fiber end.

Immunohistochemistry. Heart perfusion for rapid brain fixation was performed as described for the reconstruction of electrode position. Formalin-fixated brains were stored until slicing in storing solution (PBS with $0.1 \%$ sodium azide; catalog no. 822335 ; Merck) at $4^{\circ} \mathrm{C}$. Fiftymicrometer-thick coronal slices were cut with a vibratome in PBS and kept in storing solution in 24-well plates (catalog no. 83.3922; Sarstedt) at $4^{\circ} \mathrm{C}$ until staining. For staining, slices were briefly washed with PBS and submerged for $10 \mathrm{~min}$ in $0.25 \%$ Triton X-100 (Sigma-Aldrich) dissolved in PBS. For the following steps, slices were washed three times for $10 \mathrm{~min}$ between each solution change. Slices were submerged overnight at $4^{\circ} \mathrm{C}$ in PBS solution containing the first antibodies and for $2 \mathrm{~h}$ at room temperature in PBS solution containing the secondary antibodies. For costaining of ChAT and eYFP, goat anti-ChAT affinity-purified polyclonal antibody (catalog no. AB 144P; Merck) diluted 1:500 and rabbit antiGFP affinity purified polyclonal antibody (catalog no. ab6556; Abcam) diluted 1:1000 were used as first antibodies and Cy3-conjugated donkey anti-goat-IgG polyclonal antibody (catalog no. AP180C; Merck) diluted 1:1000 and FITC-conjugated donkey anti-rabbit-IgG polyclonal antibody (catalog no. 711-096-152; Dianova) diluted 1:1000 were used as secondary antibodies. For costaining of PV and eYFP, rabbit anti-PV serum (catalog no. PV 25; Swant) diluted 1:1000 and goat anti-GFP polyclonal antibody (ab5449; Abcam) diluted 1:1000 were used as first antibodies and Cy3-conjugated donkey anti-rabbit-IgG polyclonal antibody (catalog no. 711-156-152; Dianova) diluted 1:1000 and FITC-conjugated donkey anti-goat IgG polyclonal antibody (catalog no. 705-095-147; Dianova) diluted 1:1000 were used as secondary antibodies. After the last washing step, slices were mounted onto microscope slides (Superfrost Plus; Thermoscientific) in Aqua-Poly/Mount (Polysciences) mounting medium covered with coverslips (Engelbrecht, Medizinund Labortechnik).

LFP analysis. LFP data were digitally downsampled to $1 \mathrm{kHz}$. Power spectral density analysis was performed using the MATLAB (The MathWorks) software toolbox "FieldTrip" (Oostenveld et al., 2011). Signal preprocessing involved demeaning of the signal and $50 \mathrm{~Hz}$ line noise removal via a Fourier notch filter (bandwidth $<1 \mathrm{~Hz}$ ).

For quantification of stimulation-induced theta activity, we calculated the corrected theta peak power as follows: power spectral density was determined for every trial for a $10 \mathrm{~s}$ baseline period and a $10 \mathrm{~s}$ period beginning and ending $2 \mathrm{~s}$ later than the $10 \mathrm{~s}$ optogenetic stimulation period to account for the delayed onset and offset of induced theta oscillations and then averaged across trials for each animal. For calculation of power spectral density, the signal was tapered with Slepian sequences and multitaper fast Fourier transform was performed with a spectral smoothing of $\pm 0.5 \mathrm{~Hz}$. Theta peak power was measured relative to the power of the adjacent frequencies. The power of the adjacent frequencies contributing to the absolute power value at the theta peak frequency was estimated by linear interpolation between the minima surrounding the theta peak. If no theta peak was detectable (as usually in the baseline period), the theta peak power was considered to be zero. The optogenetic stimulation effects were then quantified as the difference between the theta peak power during stimulation and the theta peak power during the baseline period, yielding the corrected theta peak power.

For analyzing the time course of the decrease in stimulation-induced theta oscillations by the incremental hippocampal blocker mixture injections, power spectral density was determined for the $30 \mathrm{~s}$ baseline period and $10 \mathrm{~s}$ period beginning and ending $2 \mathrm{~s}$ later than the $10 \mathrm{~s}$ optogenetic stimulation period (see above) for each trial in every animal. $z$-scores were calculated for the baseline and stimulation-associated periods to reflect the change in power spectral density in units of the SD of baseline power spectral density across trials. Baseline corrected $z$-scores reflect the difference between $z$-scores of the stimulation-associated period and the $z$-scores of the baseline period.

To reflect changes in the broader low gamma range reliably, we quantified low gamma power within the frequency range from $26-48 \mathrm{~Hz}$ for $10 \mathrm{~s}$ baseline and stimulation epochs. Power spectral density plots often showed sharp peaks at exactly the stimulation frequency and its higher harmonics. Because we could not rule out the possibility that these peaks are artifacts of unspecific stimulation, we excluded the stimulation frequencies and their first two harmonics $( \pm 0.5 \mathrm{~Hz})$ from our gamma power analysis. Optogenetic stimulation effects were calculated as the difference between the gamma power during the stimulation period and the baseline period. To assess the effect size of systemic atropine application on changes in corrected theta peak power or corrected low gamma power, we compared the area under the curve over stimulation frequencies from $3-40 \mathrm{~Hz}$ preapplication versus postapplication of systemic atropine and tested for statistical significance via a Wilcoxon signed-rank test or Student's paired $t$ test.

To analyze the power change over time, time-frequency analysis using Hanning taper was performed with a $5 \mathrm{~s}$ sliding time window moving over the data in $0.625 \mathrm{~s}$ steps. A $z$-score was assigned to each time bin and frequency bin for each single trial using the full epoch trial length as the "baseline" for $z$-score calculation. $z$-scores were then averaged across trials and classical prestimulus baseline corrections were performed to make the prestimulus $z$-score values oscillate around zero. This approach has been shown to be more robust against single trial noise than classical correction methods (Grandchamp and Delorme, 2011).

For quantification of LFP power changes at the stimulation frequencies during stimulation of $\mathrm{PV}^{+}$MSDB neurons, $z$-scores were averaged across the $5 \mathrm{~s}$ midtime interval of stimulation and across $\pm 0.2 \mathrm{~Hz}$ around the stimulation frequency. 
Single unit analysis. For offline spike sorting of unit activity, the broadband signal was digitally high-pass filtered $(0.3-3 \mathrm{kHz}$, second-order elliptic filter with $0.1 \mathrm{~dB}$ of ripple in the pass band and a stop band $40 \mathrm{~dB}$ down from the peak value in the pass band). Unsupervised automatic spike detection and sorting, followed by manual adjustment of the clusters, was performed using the MATLAB (The MathWorks) software toolbox "Wave_clus" (Quiroga et al., 2004). The threshold for spike detection was set to $\sigma=$ median $\left\{\frac{|x|}{0.6745}\right\}$ (Quiroga et al., 2004), where $x$ is the band-pass filtered signal and $\sigma$ is an estimate of the SD of the background noise. Compared with the classical SD, the median-based estimate of the SD is more robust against outliers. Sorted units were classified as single units, multi units, or artifacts based on spike shape and variance, ratio between spike peak value and noise level, the interspike interval distribution of each cluster, and the presence of a refractory period $(<3 \mathrm{~ms})$ for the single units. In addition, cross-correlograms were used to verify the clustering procedure as described by Harris et al. (2000). Putative interneurons and principal cells were classified according to their spike width (time between peak and succeeding minimum) and the first moment (mean) of the autocorrelation time derived from a spike autocorrelogram from 0 to 50 ms (Csicsvari et al., 1998). Units with a characteristic "bursty" autocorrelogram (mean time $\leq 26 \mathrm{~ms}$ ) and a broad waveform (spike width $>0.75 \mathrm{~ms}$ ) were classified as putative principal cells, whereas units lacking a bursty autocorrelogram (mean time $>26 \mathrm{~ms}$ ) but possessing a narrow waveform (spike width $\leq 0.75 \mathrm{~ms}$ ) were classified as putative interneurons.

$z$-scores reflecting the change of spiking rate relative to baseline were calculated for time bins of $5 \mathrm{~s}$ by subtracting the mean firing rate of the prestimulus baseline (i.e., the first $30 \mathrm{~s}$ of recording) from the trial-averaged firing rates at each time bin and dividing these values by the SD calculated across all time bins of all trials. If the basal spiking rate was zero in each time bin of every trial but positive during stimulation periods (indicating a very strong modulation effect), the $z$-score during stimulation would be infinite due to a SD of zero during baseline. To include these units into the analysis, an SD was estimated on the assumption that there was one spike during the entire baseline period.

For the quantification of the optogenetic stimulation effect on each unit's firing rate, the $z$-scores of the time bins during stimulation $(30-40 \mathrm{~s}$ and $70-80 \mathrm{~s})$ were averaged. At the single unit level, each cell responded either with a positive or a negative change of firing rate upon stimulation. To quantify the modulation effect at the population level, we calculated a modulation index as the absolute value of the area hyperbolic sine (arsinh) of the firing rate $z$-scores during stimulation. Taking the arsinh of the $z$-scores takes into account that the $z$-score distribution resembles a lognormal distribution rather than a normal one. In contrast to a logarithmic scale, the arsinh is defined for both positive and negative values. Taking the absolute value makes the modulation index insensitive to the sign of the modulation; that is, a unit with increased spiking during stimulation is evaluated as equally modulated as a unit with decreased spiking during stimulation. Note that, at the population level, an increase of modulation would manifest itself in increasing the positive $z$-scores but decreasing the negative $z$-scores, whereas a decrease in modulation would result in shifting both positive and negative $z$-scores to zero. To quantify the effect of blocker injection compared with ACSF control injections, the difference between the modulation index before and after injection was calculated for each unit and termed the delta modulation index.

Spike-phase coupling analysis. The LFP signal was recorded from an electrode located inside or near the principal cell layer, but from which no units were extracted to prevent contribution of the spike signal itself to the phase of the LFP signal. For offline spike-phase coupling analysis, the LFP signal was downsampled to $2 \mathrm{kHz}$ and the mean of the signal was subtracted from each data point (demeaning) to make the signal oscillate around zero. After band-pass filtering in the theta range of 3-6 Hz with a second-order Butterworth filter, the left and right tails of the signal, each containing $1 \%$ of the total signal length, were multiplied with the rising and falling flanks of a modified Welch window. The instantaneous phase could then be determined via a Hilbert transformation so that each spike could be assigned its instantaneous LFP theta phase. To quantify changes in spike-phase coupling during stimulation, spike-phase coupling was analyzed for a $30 \mathrm{~s}$ baseline period and the stimulation periods (pooled $10 \mathrm{~s}$ periods of 12 and $20 \mathrm{~Hz}$ stimulation). To equalize the number of spikes under these two conditions, spikes were randomly deleted from the condition that contained more spikes. All recording sites were located inside or very close to the CA3 pyramidal cell layer.

In vitro patch-clamp recordings. Experiments in MSDB slices were performed at least 2 weeks after the virus injection. For obtaining slices, mice were deeply anesthetized with ketamine $(300 \mathrm{mg} / \mathrm{kg}$ body weight; WDT) and xylazine (60 mg/kg body weight; Bayer). Brains were removed and transferred into cold sucrose-containing carbogen-saturated ACSF containing the following (in $\mathrm{mM}$ ): $\mathrm{NaCl}, 60$; sucrose, $100 ; \mathrm{KCl}, 2.5$; $\mathrm{NaH}_{2} \mathrm{PO}_{4}, 1.25 ; \mathrm{NaHCO}_{3}, 26 ; \mathrm{CaCl}_{2}, 1 ; \mathrm{MgCl}_{2}, 5$; and D-glucose, 20; Sigma-Aldrich). Horizontal or coronal slices of the MSDB $(300 \mu \mathrm{m})$ were cut on a vibratome (Leica VT $1200 \mathrm{~S}$ ), incubated for $30 \mathrm{~min}$ at $37^{\circ} \mathrm{C}$, and transferred into ASCF containing the following (in $\mathrm{mM}$ ): $\mathrm{NaCl}, 125$; $\mathrm{KCl}, 3 ; \mathrm{NaH}_{2} \mathrm{PO}_{4}, 1.25 ; \mathrm{NaHCO}_{3}, 26 ; \mathrm{CaCl}_{2}, 2.6 ; \mathrm{MgCl}_{2}, 1.3$; and D-glucose, 15; Sigma-Aldrich). For electrophysiology, slices were transferred into a submerged chamber and superfused with carbogensaturated ACSF (speed of superfusion: $3 \mathrm{ml} / \mathrm{min}$ at $35^{\circ} \mathrm{C}$ ). Expression of ChR2-eYFP in MSDB neurons was verified using an upright fluorescence microscope (Nikon Eclipse FN1) with the following filter settings (in $\mathrm{nm}$ ): excitation: 500/24; dichroic: 520; emission: 542/27. Whole-cell patch-clamp recordings were then obtained from identified fluorescent cells or nonfluorescent cells with the help of a fluorescence microscope (Nikon Eclipse FN1) and using infrared differential interference contrast microscopy. Pipettes were made using a horizontal puller (Model P-97; Sutter Instruments) and borosilicate glass capillaries (GB150F-8P; Science Products).

Electrode resistance in the bath ranged from 3 to $5 \mathrm{M} \Omega$. The intracellular solution for whole-cell current-clamp recordings contained the following (in $\mathrm{mm}$ ): K-gluconate, 140; 4-(2-hydroxyethyl)-1-piperazineethanesulfonic acid (HEPES-acid), 5; ethylene glycol tetraacetic acid (EGTA), $0.16 ; \mathrm{MgCl}_{2}, 0.5$; sodium phosphocreatine, 5 ; and $0.3 \%$ biocytin. Voltage- and current-clamp experiments were performed with a Multiclamp 700B amplifier (Molecular Devices). Data were sampled at $10-50 \mathrm{kHz}$ with a Digidata $1322 \mathrm{~A}$ interface (Molecular Devices) controlled by pClamp Software (Molecular Devices) and stored on a hard disk for offline analysis.

In those experiments in which cholinergic axons were stimulated while recording from septal neurons, the neurons were classified based on the properties of genetically identified $\mathrm{ChAT}^{+}$or $\mathrm{PV}^{+}$neurons (Table 1). Classification was performed by H.B., who was blinded to the results of the optogenetic stimulations. As a parameter for segregating septal cell populations, the action potential half-width was used, with cells having narrow action potentials $(<0.7 \mathrm{mV})$ classified as putative $\mathrm{PV}^{+}$neurons. These cells also had large fast afterhyperpolarizations (fAHPs) compared with the putative $\mathrm{ChAT}^{+}$population $(-9.4 \pm 1.7 \mathrm{vs}$ $-3.6 \pm 1.6 \mathrm{mV}$, mean $\pm \mathrm{SEM}, p=0.027, t$ test), consistent with the properties of the genetically identified populations (Table 1). Action potential properties were analyzed as follows. Action potential threshold was determined as the voltage where the first derivative of the voltage trace exceeded $8 \mathrm{mV} / \mathrm{ms}$. The half-width was determined as the action potential width at an amplitude $50 \%$ between the threshold and peak. The fAHP amplitude was determined as the difference between the threshold and the maximal repolarization observed during the first $20 \mathrm{~ms}$ after the action potential onset. For all measurements, action potentials were selected that occurred within the first $50 \mathrm{~ms}$ after onset of the current injection. In all cells, the lowest possible current injections displaying such action potentials were selected.

In vitro optogenetic stimulation. Light stimulation of individual neurons in the MSDB (coronal slices) was performed via the microscope objective (Nikon NIR Apo 60×) using a galvanometer-based scanning system (UGA-40, DL-473; Rapp Optoelectronics) coupled to a $473 \mathrm{~nm}$ diode-pumped solid state laser (DL-473; Rapp Optoelectronics). eYFPexpressing neurons in the medial septum were targeted with $10 \mathrm{~s}$ trains of brief flashes of light (20 ms up to $2 \mathrm{~mW}$ laser power) that caused clear 
Table 1. Electrophysiological characteristics of genetically identified $\mathrm{PV}^{+}$and $\mathrm{ChAT}^{+}{ }^{\mathrm{MSDB}}$ neurons

\begin{tabular}{lccl}
\hline & $\mathrm{PV}^{+}$ & $\mathrm{ChAT}^{+}$ & $p$-value \\
\hline Passive properties & & & \\
$V_{\mathrm{m}}(\mathrm{mV})$ & $-79.7 \pm 1.7$ & $-83.2 \pm 4.6$ & 0.0360 \\
$R_{\text {inp }}(\mathrm{M} \Omega)$ & $194.7 \pm 104.9$ & $279.9 \pm 188.8$ & 0.2231 \\
$\tau_{\text {mem }}(\mathrm{ms})$ & $12.7 \pm 5.7$ & $18.5 \pm 14.4$ & 0.2529 \\
$\mathrm{Acctive} \mathrm{properties}$ & & & \\
$\mathrm{AP}_{\text {thr }}(\mathrm{mV})$ & $-53.7 \pm 8.2$ & $-51.1 \pm 4.9$ & 0.4127 \\
$\mathrm{AP}_{\text {ampl }}(\mathrm{mV})$ & $69.8 \pm 11.8$ & $62.3 \pm 6.7$ & 0.0923 \\
$\mathrm{AP}_{\text {dV/dt }}(\mathrm{mV} / \mathrm{ms})$ & $318.5 \pm 110.3$ & $133.8 \pm 63.3$ & 0.0002 \\
$\mathrm{AP}_{\text {Half-width }}(\mathrm{ms})$ & $0.31 \pm 0.08^{a}$ & $0.96 \pm 0.23$ & $1 \times 10^{-7}$ \\
$\mathrm{fAHP}^{a}(\mathrm{mV})$ & $-16.6 \pm 6.0$ & $-10.1 \pm 5.8$ & 0.0202 \\
\hline
\end{tabular}

Comparison of passive and active properties of $\mathrm{PV}^{+}(n=10)$ and ChAT ${ }^{+}(n=11)$ MSDB neurons identified by $^{+}$ genetically targeted eYFP expression. $V_{\mathrm{m}}$, Resting membrane potential; $R_{\text {inp }}$, input resistance; $\tau_{\text {mem }}$, membrane time constant; $\mathrm{AP}_{\mathrm{thr}}$, action potential threshold; $\mathrm{AP}_{\mathrm{ampl}}$, action potential amplitude; $\mathrm{AP}_{\mathrm{dV} / \mathrm{dt}}$, maximal action potential rise slope; $A P_{\text {Half-width, }}$ action potential width at half maximal amplitude. Values represent mean $\pm S D$ $p$-values ( $t$ test) and indicate statistical difference between $\mathrm{PV}^{+}$and $\mathrm{ChAT}^{+}$neurons.

${ }^{a}$ One outlier assessed by applying Chauvenet's criterion was excluded.

light-evoked responses in patch-clamp recordings. Stimulation frequencies ranged from 5 to $40 \mathrm{~Hz}$. To assess the effects of stimulation of ChR2 ${ }^{+}$ cholinergic neurons on other types of septal neurons, we used $5 \mathrm{~s}$ stimulus trains at a power of up to $60 \mathrm{~mW}$ using a $473 \mathrm{~nm}$ diode laser (LuxX 473-80; Omicron-Laserage Laserprodukte) coupled into a customized multimode light fiber ( 0.22 numerical aperture, $550 \mu \mathrm{m}$ core, BFL22550; Thorlabs) and $40 \mu \mathrm{M} 4$-aminopyridine (4-AP; Tocris Bioscience) was added to the ACSF for reliable optical stimulation. Additional recordings with longer $10 \mathrm{~s}$ stimulus trains were performed in the absence of 4-AP. In these experiments, neurons were classified based on the properties of genetically identified $\mathrm{ChAT}^{+}$or $\mathrm{PV}^{+}$neurons (Table 1). Classification was done by H.B., who was blinded to the results of the optogenetic stimulations. The end of the optical fiber was placed immediately above the brain slice surface to illuminate the MSDB. Optogenetically induced membrane depolarizations were measured relative to baseline.

Reporting of ANOVA. One-way and two-way ANOVA results are reported according to standard criteria as follows:

$$
F_{\text {factor }\left(d f_{\text {between }}, d f_{\text {within }}\right)}=\frac{V_{\text {between }}}{V_{\text {within }}}
$$

With $d f_{\text {between }}$ and $V_{\text {between }}$ as degrees of freedom and variance between the conditions of the tested factor, respectively, and $d f_{\text {within }}$ and $V_{\text {within }}$ as degrees of freedom and variance within conditions, respectively. Interaction between two factors is reported in a like manner.

\section{Results}

In vivo optogenetic activation of cholinergic MSDB neurons induces hippocampal rhythmogenesis

To achieve light-based stimulation of cholinergic MSDB neurons, we used knock-in mice expressing Cre recombinase under the control of the choline acetyltransferase promoter (ChATIRES-Cre; Fig. $1 A$ and Materials and Methods). These mice were stereotactically injected with an rAAV that allows Cre-dependent expression of channelrhodopsin 2 (ChR2-H134R) fused to the eYFP. Robust ChR2-eYFP expression could be observed in cholinergic neurons ( $43 \%, n=15$ slices from 5 mice; Fig. $1 A$ ), with $84 \%$ of the ChR2-eYFP neurons showing clear ChAT immunoreactivity. We obtained patch-clamp recordings from cholinergic MSDB neurons, which showed characteristic slow-firing properties, as described previously (Griffith and Matthews, 1986; Markram and Segal, 1990; Gorelova and Reiner, 1996; Serafin et al., 1996; Sotty et al., 2003). Light-based stimulation at $473 \mathrm{~nm}$ with a laser focused onto the neuronal somata reliably elicited action potentials, even with long-duration stimulus trains, in all cells (10 s, spiking reliability quantified as probability to elicit action potentials per light stimulus of 1 for frequencies up to $5 \mathrm{~Hz}$ and reliabilities of $0.88 \pm 0.35,0.58 \pm 0.46$, and $0.12 \pm 0.25$ for 12,20 , and $30 \mathrm{~Hz}$, respectively, mean \pm SD of $n=8$ cells; Fig. $1 B$ ).

After establishing light-based stimulation of cholinergic MSDB neurons, we turned to in vivo recordings to assess the effects of cholinergic activation on hippocampal rhythmogenesis. We first recorded LFPs from up to 32 channels of a four-shank silicon probe spanning several layers of the dorsal hippocampus (Fig. 1C). Optogenetic stimulation of ChR $2^{+}$cholinergic MSDB neurons via a light fiber implanted just above the MSDB at different stimulation frequencies caused marked changes in hippocampal rhythmicity (see Fig. $1 C$, right, for example recording). Most notably, virtually all recordings displayed an increase in theta and low gamma power, which often persisted for several seconds after cessation of stimulation. This effect was observed in all hippocampal subfields, as exemplified by power spectra and time-frequency plots of power spectral density [Fig. $1 D, E$, respectively, examples of CA1, CA3, and dentate gyrus (DG) LFP recordings, data from 11 mice with 3-6 trials per mouse]. The most robust effects were observed in the theta range (Fig. 1D,E, insets). Notably, increases in synchronization occurred in a narrow frequency range, with a suppression of adjacent frequencies (Fig. 1D, insets). We systematically varied the frequency with which light-based MSDB stimulation was performed (3-40 $\mathrm{Hz}$ ). The frequency of peak theta synchronization was significantly correlated with the frequency of MSDB stimulation (Fig. $1 F, r=0.88$ for CA1, $r=0.97$ for CA3, and $r=0.96$ for DG, $p<0.001, r=$ Pearson's correlation coefficient, $n=6$ mice, 4-6 trials per mouse). Likewise, the baseline corrected theta peak power was correlated with stimulation frequency (Fig. $1 G, r=0.68$ for CA1, $r=0.92$ for CA3, and $r=0.89$ for $\mathrm{DG}, p<0.05$ for CA 1 , and $p<0.001$ for CA3 and DG, $n=6$ mice, 4-6 trials per mouse). In addition to the correlation analyses, two-way ANOVA with hippocampal subfield as one factor and stimulation frequency as the other factor revealed a significant effect of stimulation frequency on theta peak frequency $\left(F_{\text {Stimulation frequency }(9,149)}=18.88, p<0.0001, F_{\text {Subfield }(2,149)}=1.54\right.$, $\left.p=0.217, F_{\text {Stimulation frequency }{ }^{*} \operatorname{Subfield}(18,149)}=0.45, p=0.974\right)$, and significant effects of both subfield and stimulation frequency on theta peak power $\left(F_{\text {Subfield(2,150) }}=30.39, p<0.0001, F_{\text {Stimulation frequency }(9,150)}=\right.$ $\left.1.98, p<0.05, F_{\text {Stimulation frequency }{ }^{*} \text { Subfield }(18,150)}=0.15, p>0.99\right)$. However, it should be noted that the magnitude of both effects was not very large, with a change of theta peak frequency from $3.8-4.6 \mathrm{~Hz}$ over the whole range of stimulus frequencies.

Similarly, gamma power was correlated with stimulation frequency in hippocampal subfields CA1, CA3 and DG (Fig. $1 H, r=$ 0.72 for CA $1, r=0.85$ for CA3, and $r=0.87$ for DG, $p<0.05$ for CA1, and $p<0.01$ for CA3 and DG, $n=6$ mice, $4-6$ trials per mouse). In addition, statistical analysis using two-way ANOVA with hippocampal subfield as one factor and stimulation frequency as the other factor revealed a significant impact of the hippocampal subfield and the stimulation frequency on gamma power $\left(F_{\text {Subfield }(2,150)}=5.05, p<0.01, F_{\text {Stimulation frequency }(9,150)}=\right.$ $3.32, p<0.001, F_{\text {Stimulation frequency }{ }^{*} \operatorname{Subfield}(18,150)}=0.55, p=$ $0.927)$. As expected, systemic application of atropine, a competitive antagonist of the muscarinic acetylcholine receptor (50 $\mathrm{mg} / \mathrm{kg}$ body weight), completely abolished the induction of theta rhythmic activity (Fig. $1 G, p=0.031$, Wilcoxon signed-rank test, $n=6$ mice with one value missing for CAl at $40 \mathrm{~Hz}$ stimulation, 3-6 trials per preatropine and postatropine condition and mouse, respectively). Stimulation-induced increase in low gamma activity was not significantly changed in regions CA1, CA3, or DG (Fig. $1 H, p=0.054, p=0.220$, and $p=0.241$, 

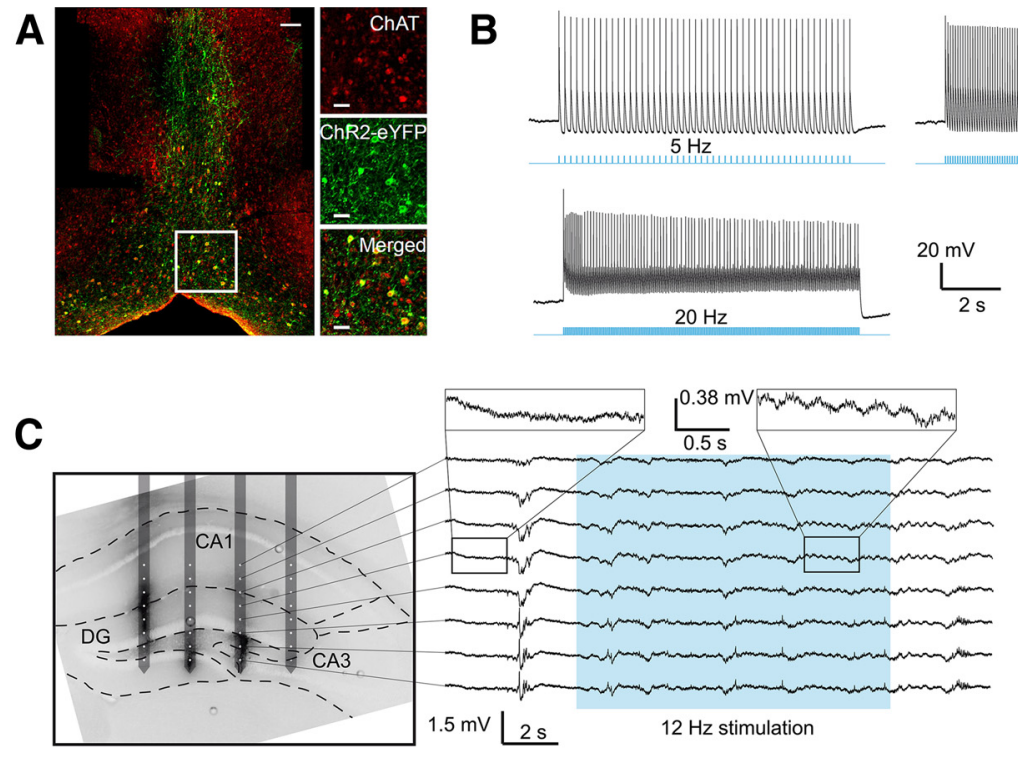
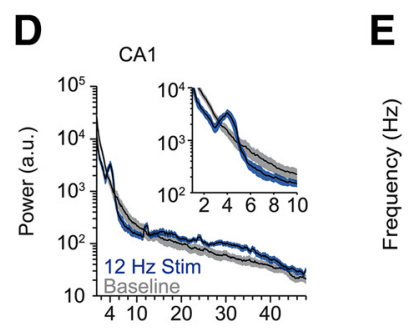

CA3

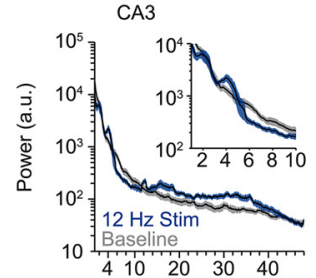

$D G$

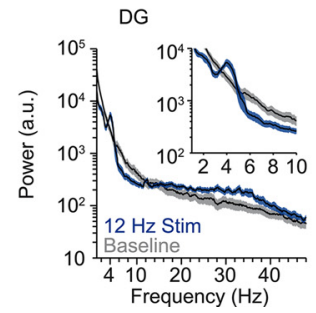

E

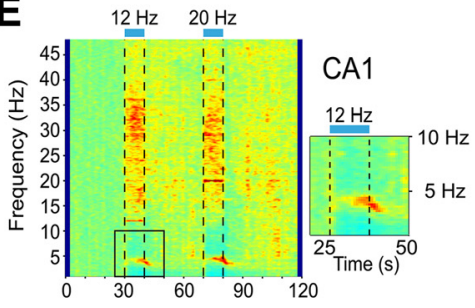

$12 \mathrm{~Hz} \quad 20 \mathrm{~Hz}$
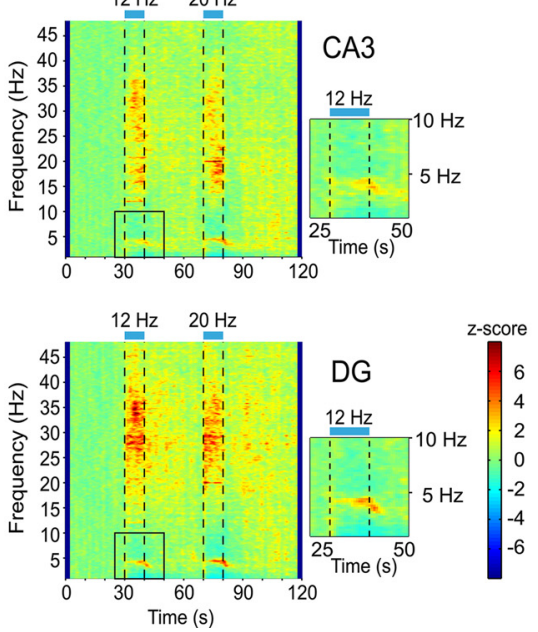

$\mathbf{F}$

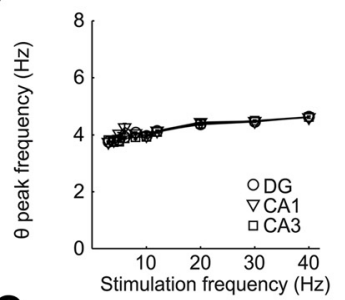

G

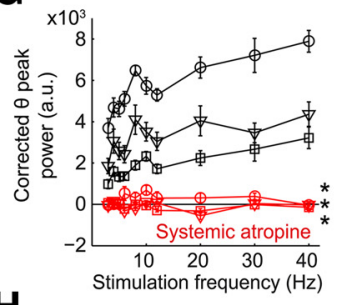

H

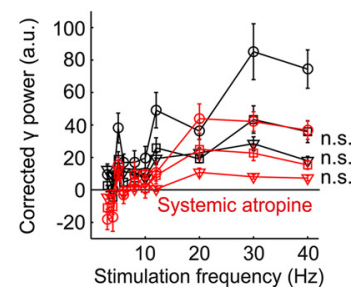

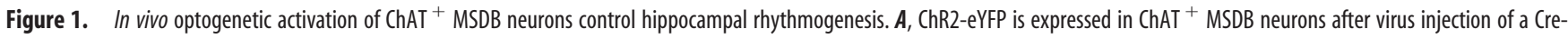
dependent rAAV into the MSDB of ChAT-Cre mice. Left, Lower-magnification photograph of ChAT-labeled (red) and ChR2-eYFP-labeled (green) cells of the medial septal region. Scale bar, $50 \mu \mathrm{m}$. Right, Higher magnification of the indicated area on the left. Scale bar, $20 \mu \mathrm{m}$. B, In vitro entrainment of a ChAT ${ }^{+}$-ChR2 ${ }^{+}$MSDB neuron evoked by repetitive $473 \mathrm{~nm}$ light stimulation with $20 \mathrm{~ms}$ light pulses. C, Left, Fifty-micrometer slice of the dorsal hippocampus overlaid with the schematic drawing of the in vivo electrode recording positions. Silicon probe shanks were coated with dextran-biotin for post hoc staining of shank-adjacent tissue. Right, Example trace of LFPs recorded from the eight electrode contacts of one silicon probe shank during $473 \mathrm{~nm}$ light stimulation at $12 \mathrm{~Hz}$ with 20 ms light pulses. $D$, Power spectra of a 10 s time interval shifted $2 \mathrm{~s}$ in relation to the period of stimulation at $12 \mathrm{~Hz}$ to account for the delayed on- and offset of stimulation-induced theta oscillations for hippocampal subfields CA1, CA3, and DG compared with power spectra of a 10 s baseline period. Black lines represent mean and blue and gray shading represent SEM of spectral power associated with stimulation-induced and baseline activity, respectively ( $n=11$ mice, data for one mouse reflect the mean across $3-6$ trials). $\boldsymbol{E}$, Time-frequency plots of power spectral density $z$-scores from LFPs recorded in hippocampal subfields CA1, CA3, and DG during light stimulation of ChAT ${ }^{+}$-ChR2 ${ }^{+}$MSDB neurons for 10 s intervals at 12 or $20 \mathrm{~Hz}$. Insets show theta power increase and suppression of adjacent frequency bands during $12 \mathrm{~Hz}$ stimulation. $\boldsymbol{F}$, Stimulation-induced theta peak power frequency in hippocampal subfields CA1, CA3, and DG increased linearly with frequency of stimulation ( $r=0.88$ for $C A 1, r=0.97$ for $C A 3$, and $r=0.96$ for $D G, p<0.001, r=$ Pearson's correlation coefficient). G, Stimulation-induced changes in corrected theta peak power in hippocampal subfields CA1, CA3, and DG increased linearly with stimulation frequencies ( $r=0.68$ for CA1, $r=0.92$ for CA3, and $r=0.89$ for DG, $p<0.05$ for CA1, and $p<0.001$ for CA3 and DG). Systemic atropine injections ( $50 \mathrm{mg} / \mathrm{kg}$ body weight) abolished theta induction in hippocampal subfields CA1, CA3, and DG ( ${ }^{*} p<0.05$, Wilcoxon signed-rank test). $\boldsymbol{H}$, Stimulation-induced gamma band ( $26-48 \mathrm{~Hz}$ ) power in hippocampal subfields CA1, CA3, and DG for different frequencies of light stimulation before and after systemic atropine injection ( $50 \mathrm{mg} / \mathrm{kg}$ body weight). $\mathrm{n.S}$., Not significant, Wilcoxon signed-rank test or Student's paired $t$ test. $\boldsymbol{F}-\boldsymbol{H}$, Symbols and error bars represent mean \pm SEM for six mice with one value missing for CA1 at $40 \mathrm{~Hz}$ stimulation in $\boldsymbol{F}$. 
respectively, paired $t$ test, $n=6$ mice, $3-6$ trials per preatropine and postatropine condition and mouse, respectively).

Interneuron and principal cell firing is differentially modulated by cholinergic MSDB neurons

To assess how activation of cholinergic MSDB neurons affects the activity of hippocampal neurons in vivo, we identified spikes from the high-pass-filtered LFP signal and clustered the spikes into single units (see Materials and Methods). Within the CA3 region, we discriminated putative interneurons and principal cells on the basis of their waveform and autocorrelogram according to previously published criteria (Fig. 2A, B; Csicsvari et al., 1998). Using this classification, most of the recorded units could be clearly assigned (Fig. 2B; 582/671 neurons from 42 mice, 197 putative interneurons from 36 mice, 385 putative principal cells from 39 mice, 3-10 trials per mouse). Most interneurons responded to the stimulation with an increased spiking rate, whereas the majority of principal neurons showed decreased spiking rates (Fig. $2 C$ for examples; Fig. 2D). Accordingly, the mean normalized spiking rate was significantly increased for putative interneurons, but decreased for putative principal cells during stimulation (Fig. $2 E, \chi_{(23,4704)}^{2}=128.2, p<0.0001$, and $\chi_{(23,9216)}^{2}=990.3, p<0.0001$, respectively, Kruskal-Wallis test for difference between $0.5 \mathrm{~s}$ time bins; ${ }^{*}$ indicates significant difference between one time interval against each of the baseline time intervals, $p<0.05$, Tukey-Kramer post hoc test). In a subset of these recordings, we applied systemic atropine (see Materials and Methods). This allowed us to determine atropine effects on light-evoked responses in 16 putative interneurons and 35 putative principal neurons. Systemic atropine application diminished cholinergic modulation of putative interneurons, whereas the modulation of putative principal cells was not significantly altered (Fig. $2 F, G$; ${ }^{*}$ indicates significant difference between modulation indices, $p<0.05$, Wilcoxon signed-rank test, $n=16$ putative interneurons from six mice, and $n=35$ putative principal cells from five mice, 3-6 trials per preatropine and postatropine condition and mouse, respectively).

\section{Stimulation-induced hippocampal} theta requires an intraseptal relay Cholinergic MSDB neurons give rise to septo-hippocampal projection fibers as well as intraseptal connections to GABAergic and glutamatergic MSDB
A

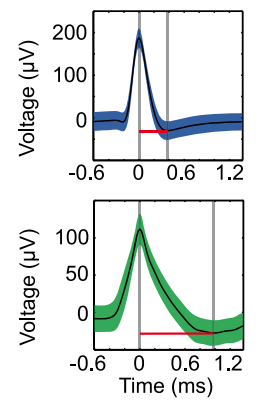

C
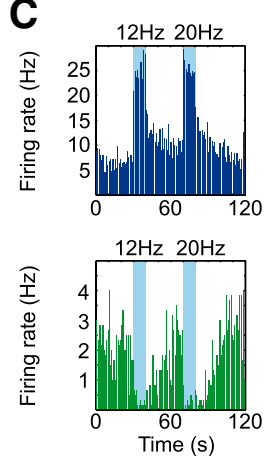

$\mathbf{F}$

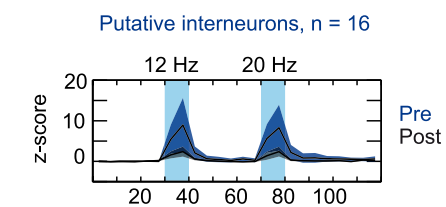

G

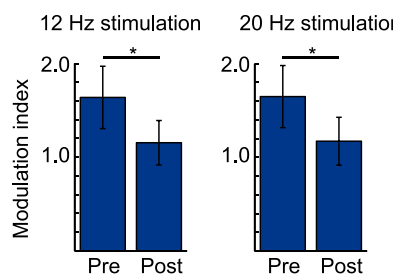

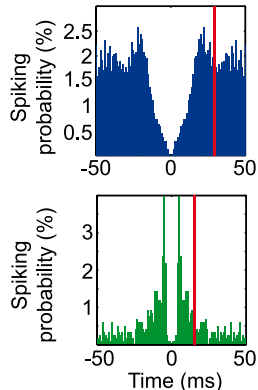

D

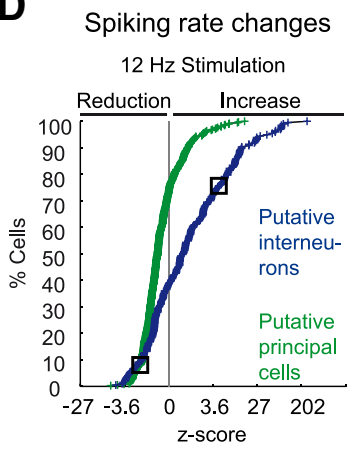

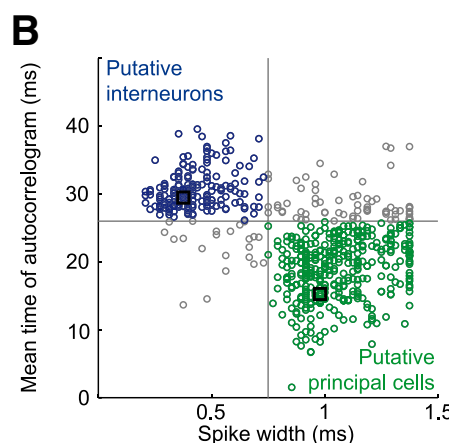

E
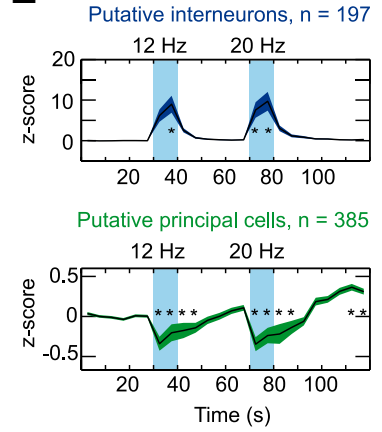

\section{Systemic atropine (Pre vs. Post)}
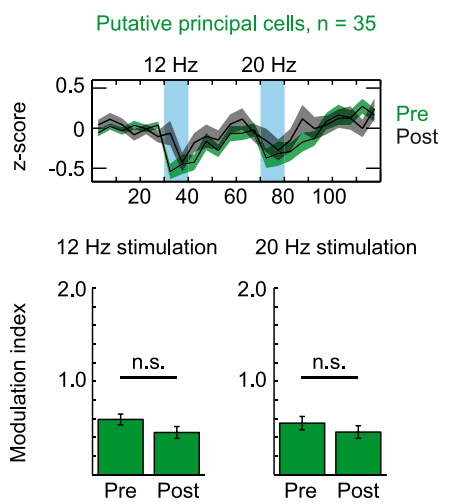

Figure 2. Stimulation of $\mathrm{ChAT}^{+} \mathrm{MSDB}$ neurons results in a net increase of interneuron firing and a net decrease of principal cell firing in the hippocampal CA3 subfield. $A$, Waveform (mean \pm SD) and spike autocorrelogram of a putative interneuron (top) and a putative principal cell (bottom) recorded in area CA3 of the dorsal hippocampus. Red lines in left panels indicate the spike width, red lines in right panels indicate the mean time of the autocorrelogram. $\boldsymbol{B}$, Clustering of cells into putative interneurons or putative principal cells based on the spike width and the first moment (mean time) of the autocorrelogram, black squares mark the cells in $\boldsymbol{A}$. Single units were recorded from a total of 42 mice during 3-10 trials per mouse: 197 units from 36 mice were clustered as putative interneurons, and 385 units from 39 mice were clustered as putative principal cells. C, Firing rate histograms of the putative interneuron (top) and principal cell (bottom) shown in $\boldsymbol{A}$. Blue background indicates $10 \mathrm{~s}$ time intervals of light stimulation of cholinergic MSDB neurons at 12 or $20 \mathrm{~Hz}$. D, Cumulative cell density plot of firing rate $z$-scores calculated for the $10 \mathrm{~s} 12 \mathrm{~Hz}$ stimulation duration. Black squares mark cells in $\boldsymbol{A}$ and C. $E$, Mean (indicated by black line) \pm SEM (indicated by colored area) of firing rate $z$-scores for putative interneurons (top) and putative principal cells (bottom). $z$-scores were calculated for $5 \mathrm{~s}$ time intervals. Firing rate $z$-scores increased for putative interneurons during 12 and $20 \mathrm{~Hz}$ light stimulation, whereas putative principal cells showed a prolonged decrease of firing rate $z$-scores during and after light stimulation at 12 and $20 \mathrm{~Hz}$. Blue backgrounds indicate time intervals of light stimulation $\left({ }^{*} p<0.05\right.$ for the difference of an individual $5 \mathrm{~s}$ time interval from each $5 \mathrm{~s}$ time interval of the baseline period, Kruskal-Wallis one-way ANOVA followed by Tukey-Kramer post hoc test). $\boldsymbol{F}$, Mean \pm SEM of firing rate $z$-scores for putative interneurons (left) and principal cells (right) before (black line and colored area indicate mean and SEM, respectively) and after (black line and gray area indicate mean and SEM, respectively) systemic atropine application $(50 \mathrm{mg} / \mathrm{kg}$ body weight, i.p.) to 6 of 42 mice. $G$, Data represent mean \pm SEM of modulation indices (see Materials and Methods) for putative interneurons (blue, left) and putative principal cells (green, right) preapplication and postapplication of systemic atropine for stimulation trains at 12 and $20 \mathrm{~Hz}\left({ }^{*} p<0.05\right.$ for difference in modulation index after systemic atropine application, Wilcoxon signed-rank test). $\boldsymbol{F}, \mathbf{G}$, Sixteen putative interneurons from six mice and 35 putative principal cells from five mice. 


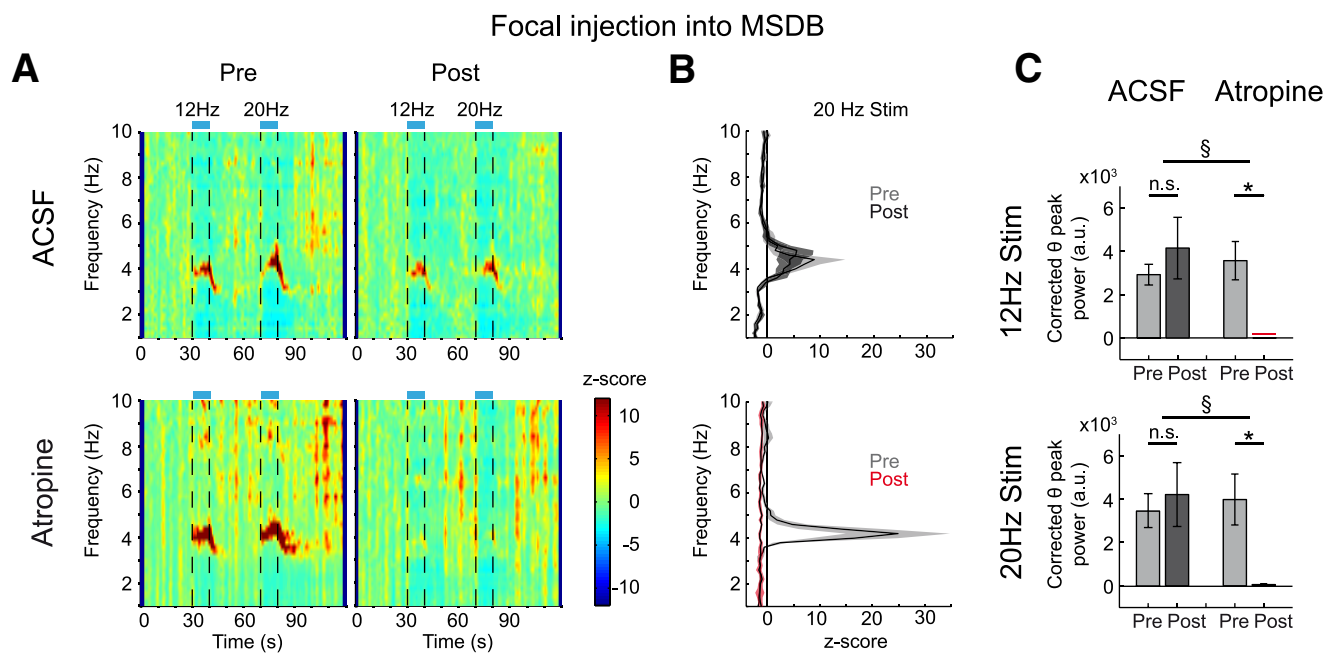

Focal injection into dorsal hippocampus

D
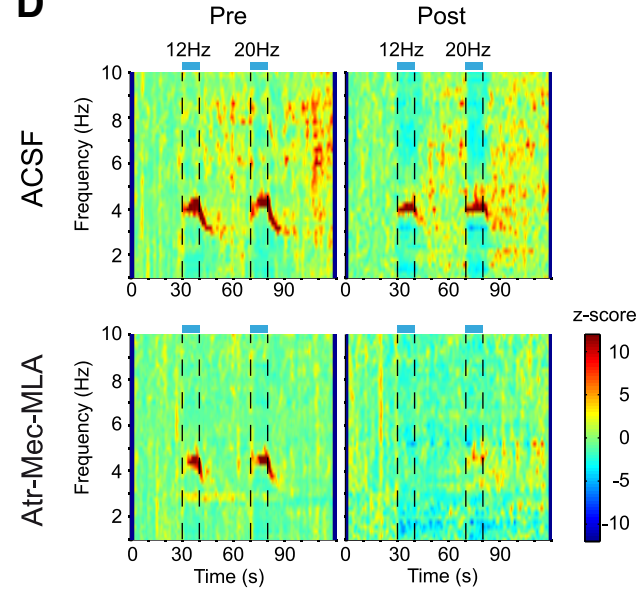

G

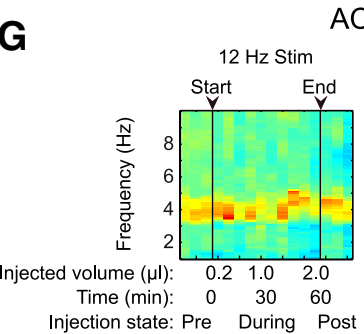

ACSF

$20 \mathrm{~Hz}$ Stim

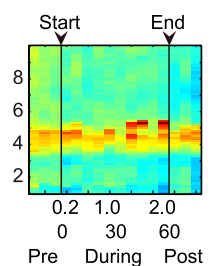

E
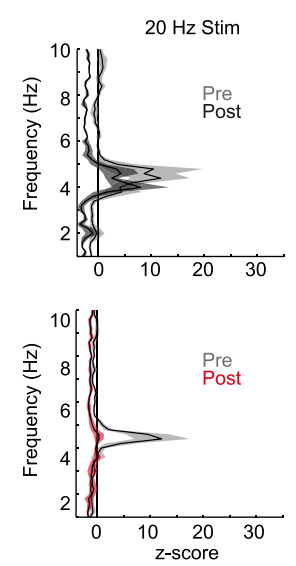

$\mathbf{F}$

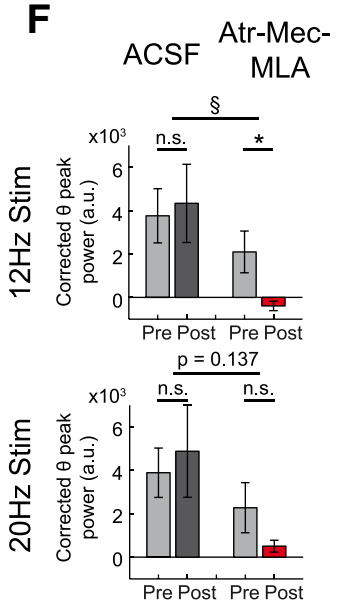

Figure 3. Hippocampal theta rhythm induced by stimulation of cholinergic MSDB neurons requires an intraseptal relay. $A$, Time-frequency plots of power spectral density $z$-scores from LFPs recorded in hippocampal subfield CA1 during light stimulation of cholinergic MSDB neurons for 10 s intervals at 12 or $20 \mathrm{~Hz}$. Top, Animal before and after focal ACSF injection. Bottom, Same prefocal and postfocal MSDB injections of atropine $(7.2 \mathrm{~mm})$ in a different animal. $z$-scores were averaged across trials. $\boldsymbol{B}$, Mean \pm SEM of power spectral density $z$-scores averaged across the $20 \mathrm{~Hz}$ stimulation time interval (72.5- $80 \mathrm{~s}$ of recording) for preapplication and postapplication conditions $[n=6$ mice for ACSF injections (top), and $n=5$ mice for atropine injection (bottom)]. C, Mean \pm SEM of the corrected theta peak power difference for $12 \mathrm{~Hz}$ stimulation (top) or $20 \mathrm{~Hz}$ stimulation (bottom) for the ACSF- and atropine-injected groups. Stimulation-induced theta synchronization is abolished after focal atropine injection into the MSDB ( ${ }^{*} p<0.05$, paired $t$ test. $\S p<0.05, t$ test, n.s. $=$ not significant, same mice as in $B, 3-6$ and $4-6$ trials for pre- and post-ACSF injection condition per mouse, respectively, and 5-7 and 4-5 trials for preatropine and postatropine injection condition per mouse, respectively). $\boldsymbol{D}$, Time-frequency analysis of hippocampal power spectral density before and after focal injections into the dorsal hippocampus. One animal shown for ACSF (top) and one for a blocker mixture of Mec, $10 \mathrm{~mm}, \mathrm{MLA}, 20 \mu \mathrm{M}$, and atropine (Atr), $7.2 \mathrm{mM}$ (bottom). E, Mean \pm SEM of power spectral density $z$-scores averaged over the $20 \mathrm{~Hz}$ stimulation time window (72.5- 80 s of recording) before and after drug application [ $n=3$ mice for ACSF injections (top), $n=5$ mice for Atr-Mec-MLA injections (bottom)]. $F$, Mean \pm SEM of the corrected theta peak power difference for $12 \mathrm{~Hz}$ stimulation (top) or $20 \mathrm{~Hz}$ stimulation (bottom) for the ACSF- and blocker-injected groups (statistics as in $\boldsymbol{C}$, same mice as in $\boldsymbol{E}$, 6 and 9 - 10 trials per pre- and post-ACSF injection condition per mouse, respectively, and 3-7 and 5-10 trials per pre- and post-Atr-Mec-MLA injection condition per mouse, respectively). $\boldsymbol{G}, \boldsymbol{H}$, Change of the stimulation-induced theta oscillations by incremental hippocampal injections of ACSF (G) versus Atr-Mec-MLA $(\boldsymbol{H})$. Baseline corrected mean $z$-scores reflect the change of power spectral density upon $12 \mathrm{~Hz}$ or $20 \mathrm{~Hz}$ stimulation (left or right, respectively) for the 5 animals with cholinergic blocker injections and the 3 ACSF-injected mice (see Materials and Methods for calculation of $z$-scores). Arrowheads mark the start and end of the microinjection series. During the injection series, one trial was recorded immediately after each of the 10 $200 \mathrm{nl}$ microinjections (every 5-6 min). 
A
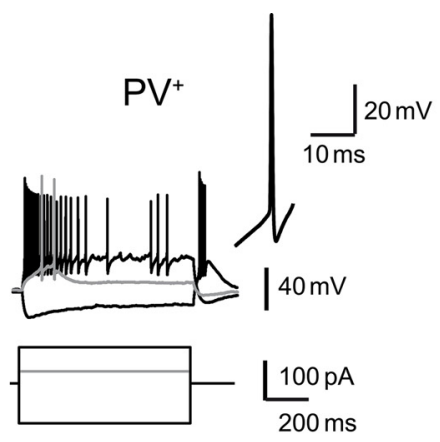

C

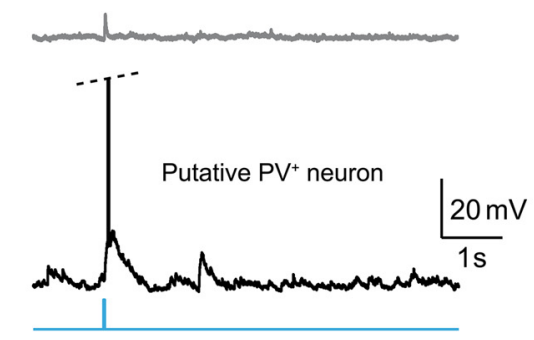

E

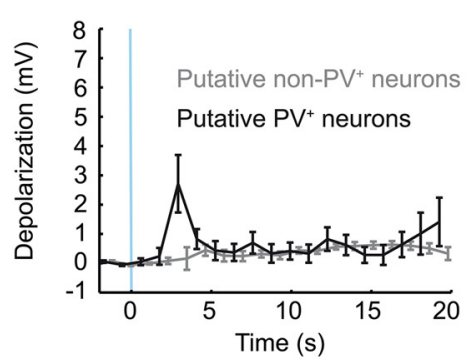

G
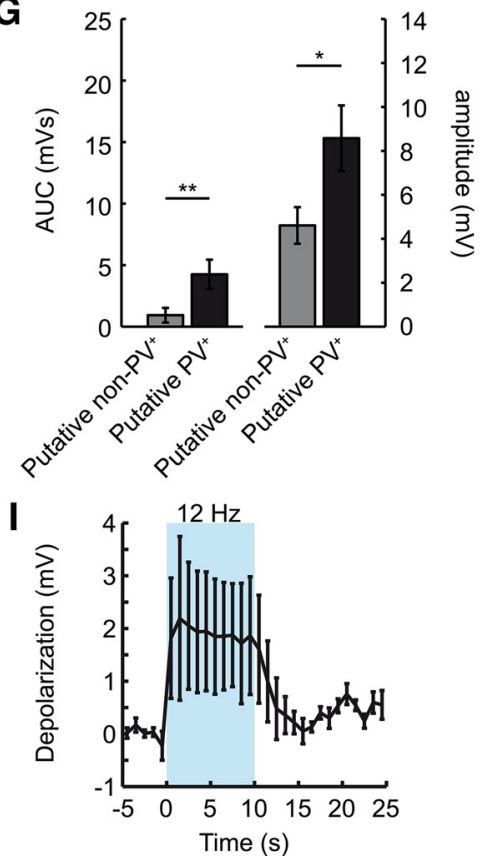

B

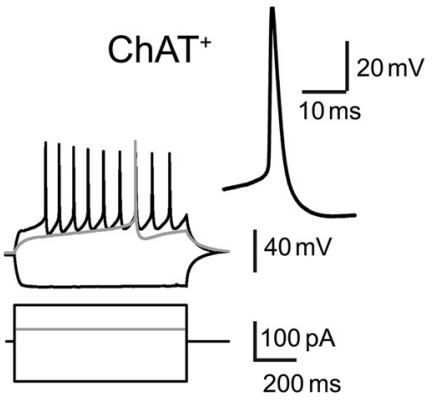

D

Putative non-PV+ neuron

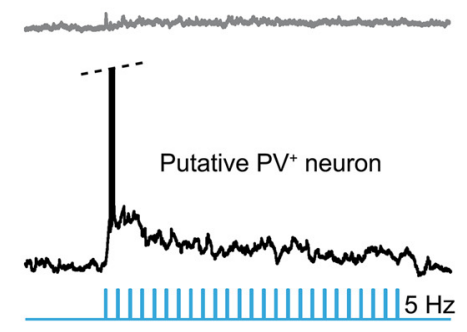

F

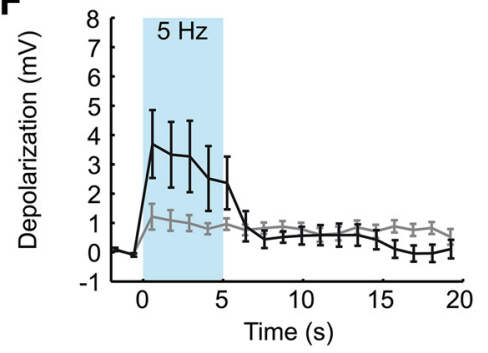

H

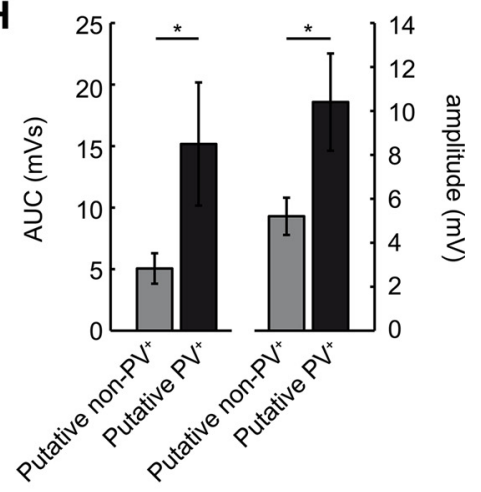

$20 \mathrm{~Hz}$

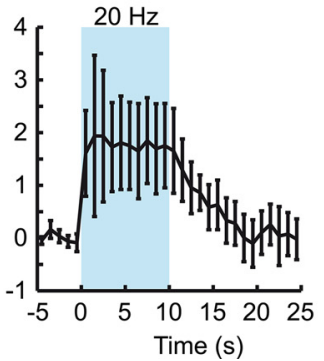

Figure 4. Cholinergic MSDB neurons activate putative $\mathrm{PV}^{+}$neurons. $\boldsymbol{A}, \boldsymbol{B}$, Representative recordings from genetically identified $\mathrm{PV}^{+}(\boldsymbol{A})$ and $\mathrm{ChAT}^{+}$neurons $(\boldsymbol{B})$ in the slice preparation. Top and bottom traces correspond to voltage recordings and current injections, respectively. Gray traces correspond to threshold current injections. Insets show the first action potential generated within $50 \mathrm{~ms}$ of onset of the currentinjection and depict thetypical properties of these two cell types (see also Table 1). C, D, Representative recordings from putative $\mathrm{PV}^{+}$and non-PV ${ }^{+}$MSDB neurons (single stimulation in C, $5 \mathrm{sstimulation}$ train at $5 \mathrm{~Hz}$ in $\boldsymbol{D}$ ) during optogenetic activation of cholinergic neurons in MSDB slices. $E, F$, Quantification of the average depolarization after stimulation. Average voltage in $1 \mathrm{~s}$ time bins is plotted. Blue background indicates period of light stimulation (single stimulation and $5 \mathrm{~Hz}$ train in $\boldsymbol{E}, \boldsymbol{F}$, respectively). $\boldsymbol{G}, \boldsymbol{H}$, The area under the curve (AUC, left $y$-axis) and average peak amplitude (right $y$-axis) of the light-evoked depolarizations within 5 s evoked by single stimulations $\left(\boldsymbol{G},{ }^{*} p<0.05,{ }^{* *} p<0.01, t\right.$ test, $n=9$ and 19 for putative $\mathrm{PV}^{+}$and non-PV ${ }^{+}$neurons, respectively) or trains $\left(\boldsymbol{H},{ }^{*} p<0.05, n=10\right.$ and 16 for putative $\mathrm{PV}^{+}$and non-PV ${ }^{+}$neurons, respectively). II, Light-evoked depolarizations lasted over the full 10 s time interval of the stimulus train used in the in vivo experiments. Left and right are data for stimulus trains at 12 and $20 \mathrm{~Hz}$, respectively. Data are presented as mean \pm SEM of four (out of five) recorded cells showing an initial depolarization. 
A
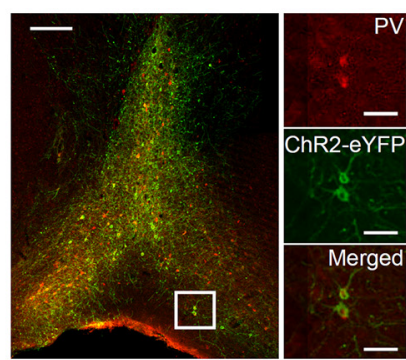

C

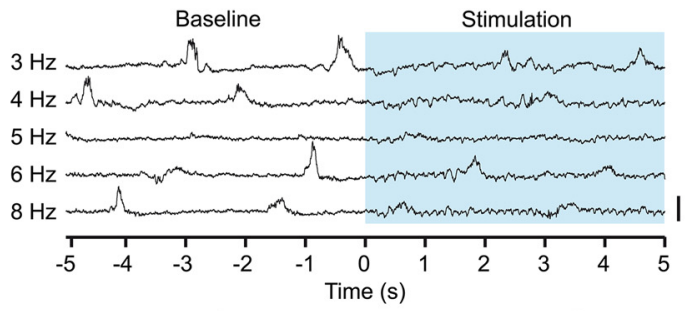

D

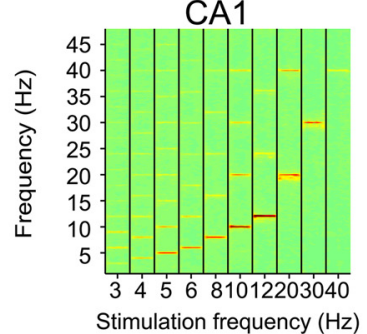

$\mathbf{E}$

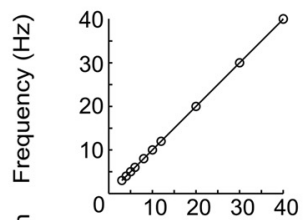

F

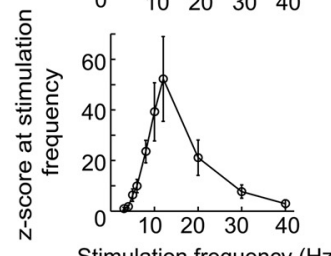

G

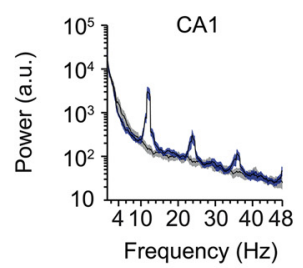

H

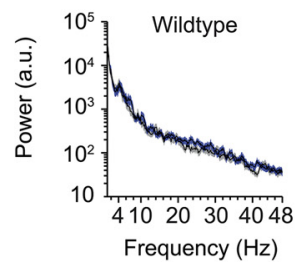

CA3
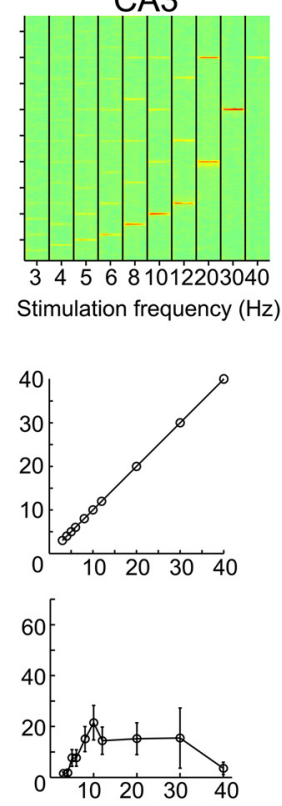

Stimulation frequency $(\mathrm{Hz})$
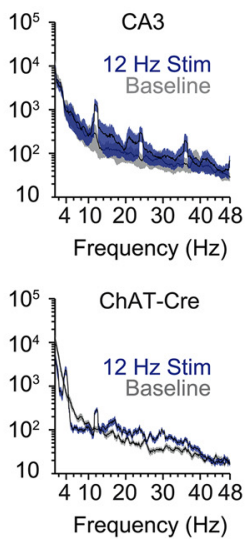

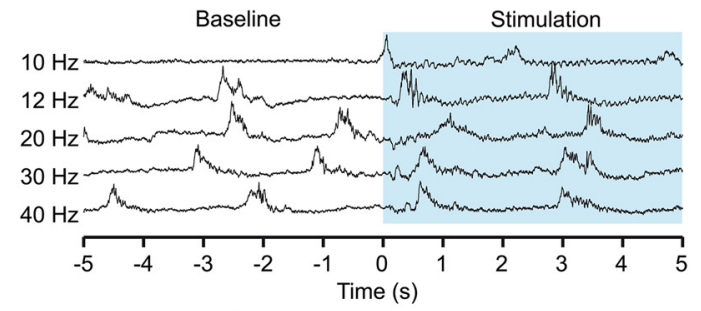

DG
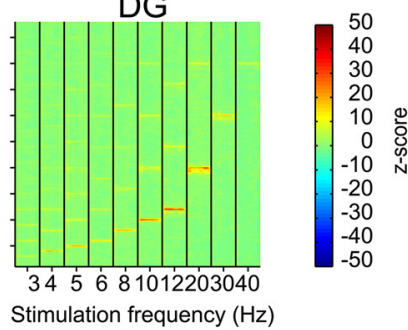

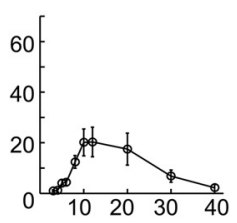

Stimulation frequency $(\mathrm{Hz})$
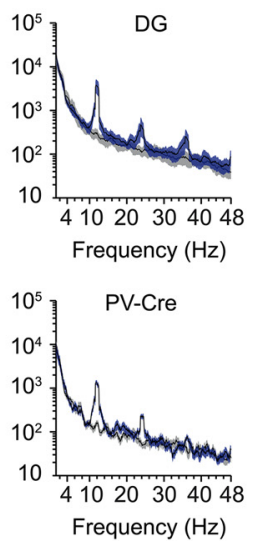

Figure 5. $\mathrm{PV}^{+} \mathrm{MSDB}$ neurons are able to recruit hippocampal ensembles with high temporal precision. $A$, ChR2-eYFP is expressed in $\mathrm{PV}{ }^{+}$MSDB neurons after virus injection of a Cre-dependent rAAV into the MSDB of PV-Cre mice. Left, Lower-magnification photograph of PV-labeled (red) and ChR2-eYFP-labeled (green) cells of the medial septal region. Scale bar, $200 \mu \mathrm{m}$. Right, Higher magnification of the indicated area on the left. Scale bar, $50 \mu \mathrm{m}$. B, In vitro entrainment of a $\mathrm{PV}^{+}-$ChR2 ${ }^{+}$MSDB neuron evoked by repetitive $473 \mathrm{~nm}$ light stimulation with $20 \mathrm{~ms}$ light pulses. $C$, Raw traces of hippocampal field potentials recorded in stratum radiatum of CA1 depicting the oscillatory change upon the onset of light-stimulation of PV ${ }^{+} \mathrm{MSDB}$ neurons. Each line represents data for one of the different stimulation frequencies ranging from 3 to $40 \mathrm{~Hz}$. Blue area indicates the time period of stimulation with the zero time point indicating the onset of the stimulation train. Scale bar, $1 \mathrm{mV}$. D, Time-frequency plots of power spectral density $z$-scores of LFPs recorded in vivo during light stimulation of $\mathrm{PV}^{+}{ }_{-}$-ChR2 ${ }^{+} \mathrm{MSDB}$ neurons. Columns show $10 \mathrm{~s}$ time intervals of different stimulation frequencies in the range of $3-40 \mathrm{~Hz}$. Plots show mean values for hippocampal subfields CA1, CA3, and DG $[n=5$ animals, $1-9$ trials (median $=6$ ) per mouse (Figure legend continues.) 
neurons. Both of these neuron types also provide projections to the cortex and hippocampus. Therefore, it is conceivable that some effects of activating cholinergic MSDB neurons might be mediated via an intraseptal relay. We assessed the relevance of such an indirect pathway for theta synchronization. We injected atropine $(300 \mathrm{nl}, 7.2 \mathrm{~mm}$, see Materials and Methods) focally into the MSDB while optogenetically stimulating cholinergic MSDB neurons (Fig. $3 A$, bottom). We used atropine because muscarinic $\mathrm{ACh}$ receptors play a major role in regulating septo-hippocampal GABAergic neurons (Alreja et al., 2000). Control animals were injected with ACSF (Fig. $3 A$, top). Atropine, but not ACSF injection into the MSDB, caused a complete block of optogenetically induced hippocampal theta oscillations [Fig. $3 B, C$; ${ }^{\star}$ indicates significant difference between preapplication and postapplication conditions, $p<0.05$, paired $t$ test, $\$$ indicates significant differences between $\operatorname{ACSF}$ ( $n=6$ mice) and atropine groups ( $n=5$ mice), $p<0.05, t$ test $]$. These results indicate that an intraseptal relay is mandatory for the generation of cholinergic theta oscillations in the hippocampus. But is synaptic acetylcholine release by MSDB projections to the hippocampus also important for hippocampal theta generation? We focally injected a blocker mixture of nicotinic and muscarinic acetylcholine receptor antagonists [mecamylamine (Mec), $10 \mathrm{~mm}$, methyllycaconitine (MLA), $20 \mu \mathrm{M}$, and atropine, $7.2 \mathrm{~mm}$, see Materials and Methods) into the dorsal hippocampus close to the recording site (see Fig. 3D for example experiments with ACh receptor blockers and ACSF injection). We chose to block both muscarinic and nicotinic ACh receptors because, in the hippocampus, most interneurons show strong excitation via nicotinic ACh receptors (Ji and Dani, 2000). In most experiments, theta induction was strongly inhibited after blocker, but not after ACSF injection [Fig. 3E, F; ${ }^{*}$ indicates significant difference between preapplication and postapplication conditions, $p<$ 0.05 , paired $t$ test, $\$$ indicates significant differences between $\operatorname{ACSF}(n=3$ mice) and Atr-Mec-MLA group ( $n=5$ mice), $p<0.05, t$ test]. After the start of the injection series for Atr-Mec-MLA, but not for ACSF, average stimulation-evoked theta power shows an incremental reduction (Fig. $3 \mathrm{G}, \mathrm{H}$; time to $50 \%$ of the effect obtained with exponential fitting $26.1 \mathrm{~min}$ after beginning the first injection, $20 \mathrm{~Hz}$ stimulation). This is consistent with a local effect of these blockers, although we cannot exclude that blockers may spread to more distant brain regions at later stages.

Our findings demonstrate that both hippocampal and septal ACh is required for proper induction of theta oscillations. In particular, the requirement for intraseptal ACh suggests

\footnotetext{
$\overline{\text { (Figure legend continues.) and stimulation condition]. } \boldsymbol{E} \text {, Stimulation-induced peak-power }}$ frequencies precisely match the stimulation frequencies in all five animals tested. Error bars are within the symbol size. $F$, $Z$-scores reflecting the LFP power change at the frequency of stimulation during the time of stimulation for the different stimulation frequencies. Note that there is a peak at $\sim 10 \mathrm{~Hz}$ for hippocampal subfields CA1, CA3, and DG. Data represent mean \pm SEM across five animals. G, Power spectra for hippocampal subfields CA1, CA3, and DG during the $10 \mathrm{~s}$ time interval of stimulation at $12 \mathrm{~Hz}$ (traces with blue shading) compared with a $10 \mathrm{~s}$ baseline period (traces with gray shading). Black lines and shading represent mean \pm SEM, respectively. $\boldsymbol{H}$, Black lines and shading represent mean \pm SEM of power spectra of $10 \mathrm{~s}$ baseline activity (traces with gray shading) and the $10 \mathrm{~s}$ time interval of stimulation at $12 \mathrm{~Hz}$ (traces with blue shading) for a nontransduced wild-type compared with a ChAT-Cre and PV-Cre mouse, both virus-injected with ChR2-eYFP into the MSDB. Data for these three mice were obtained using the same experimental setup with the same silicon probe for all mice ( $n=5$ trials for the wild-type and ChAT-Cre mouse, $n=3$ trials for the PV-Cre mouse).
}

that intraseptal connectivity is essential for mediating hippocampal theta induction. We therefore examined the effects of cholinergic neuron activation on other types of septal neurons. We first characterized genetically identified $\mathrm{ChAT}^{+}$and $\mathrm{PV}^{+}$GABAergic neurons in the slice preparation (see Materials and Methods) and characterized their functional properties (Fig. $4 A, B$ ). $\mathrm{PV}^{+}$neurons were characterized by narrow action potentials with a fast upstroke and prominent fAHPs. These characteristics set them apart from $\mathrm{ChAT}^{+}$neurons (Table 1). Subsequently, we activated cholinergic neurons optogenetically in septal slices and recorded from non-ChR2expressing medial septal neurons. Non-ChR2-expressing neurons were classified into putative $\mathrm{PV}^{+}$and other neurons based on their functional properties. Whereas a single light stimulation pulse elicited only small effects in non- $\mathrm{PV}^{+}$neurons, it caused a slow depolarization in putative $\mathrm{PV}^{+}$neurons (Fig. 4C, top and bottom traces, respectively, Fig. 4E, quantification of average amplitude and area under the curve within 5 s after stimulation in Fig. $4 G ;{ }^{\star}{ }^{\star *}$ indicate significant difference, ${ }^{\star} p<0.05,{ }^{*} p<0.01, t$ test, $n=9$ and 19 for $\mathrm{PV}^{+}$and non- $\mathrm{PV}^{+}$neurons, respectively). Trains of stimulations reliably elicited longer-lasting slow depolarizations in both neuron types (Fig. $4 D, F$ ) that were significantly larger in putative $\mathrm{PV}^{+}$neurons (Fig. $4 H$; ${ }^{*}$ indicates significant difference, ${ }^{*} p<0.05$, $t$ test, $n=$ 10 and $n=16$ for $\mathrm{PV}^{+}$and non- $\mathrm{PV}^{+}$neurons, respectively). We additionally recorded from five putative $\mathrm{PV}^{+}$neurons using $10 \mathrm{~s}$ stimulation trains, an identical duration as used for the in vivo experiments. We observed a depolarization in four of five neurons. Notably, this depolarization lasted over the full $10 \mathrm{~s}$ time interval of the stimulus train (Fig. 4I; only the four cells showing a depolarization are shown). Of the 15 putative $\mathrm{PV}^{+}$neurons, seven were depolarized sufficiently to generate action potentials during light-stimulation, with the time at which action potentials occurred being very variable.

These results suggest that $\mathrm{PV}^{+}$septal neurons may be recruited by cholinergic activation and play a role in driving hippocampal theta rhythms. Indeed, $\mathrm{PV}^{+} \mathrm{MSDB}$ neurons selectively innervate hippocampal interneurons and have long been suggested to be important for hippocampal theta rhythmicity via disinhibition of principal cells (Freund and Antal, 1988; Serafin et al., 1996; Tóth et al., 1997; Hangya et al., 2009). After expression of $\mathrm{ChR} 2$ in $\mathrm{PV}^{+}$septal neurons using rAAV-mediated gene transfer (Fig. 5A), brief light pulses resulted in reliable stimulation of these neurons, even during long stimulation trains of $10 \mathrm{~s}$ (spiking reliability per stimulus pulse of 1 for frequencies up to 20 $\mathrm{Hz}$, and reliabilities of $0.92 \pm 0.09$ and $0.45 \pm 0.43$ for 30 and 40 $\mathrm{Hz}$, respectively, mean $\pm \mathrm{SD}$ of $n=4$ cells; Fig. $5 B)$. We performed in vivo light stimulation of $\mathrm{PV}^{+}$neurons in the MSDB and simultaneously recorded with a silicon probe in the hippocampus ( $n=5$ mice). Optogenetic stimulation of $\mathrm{PV}^{+}$MSDB neurons caused a recruitment of hippocampal rhythmicity at precisely the stimulation frequency (Fig. $5 C-E$ ), unlike for the stimulation of $\mathrm{ChAT}^{+} \mathrm{MSDB}$ neurons or light stimulation in untransduced wild-type mice (Fig. 5G,H). Remarkably, the spectral power of the oscillatory activity showed a clear frequency dependence (Kruskal-Wallis test, $\chi_{(9,40)}^{2}=36.6, p<0.0001$ for CA1, $\chi_{(9,40)}^{2}=21.6, p<0.05$ for CA3, and $\chi_{(9,40)}^{2}=33.6, p<$ 0.001 for $D G)$. There was a maximum within all subregions at $\sim 10 \mathrm{~Hz}$ stimulation frequency, indicating a preferred frequency of the MSDB-hippocampal network oscillation (Fig. $5 F$ ). The distinct nature of the effects of stimulating $\mathrm{PV}^{+} \mathrm{MSDB}$ neurons can be clearly appreciated, as well as the lack of any effect in wild-type animals. 
A

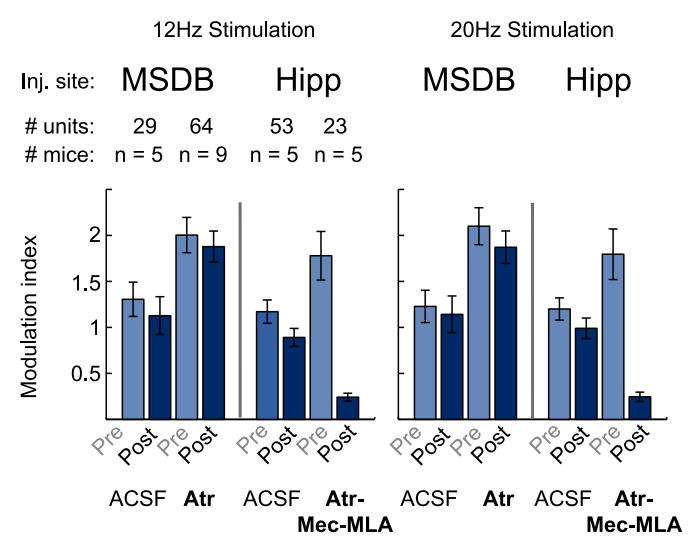

B
Putative principal cells
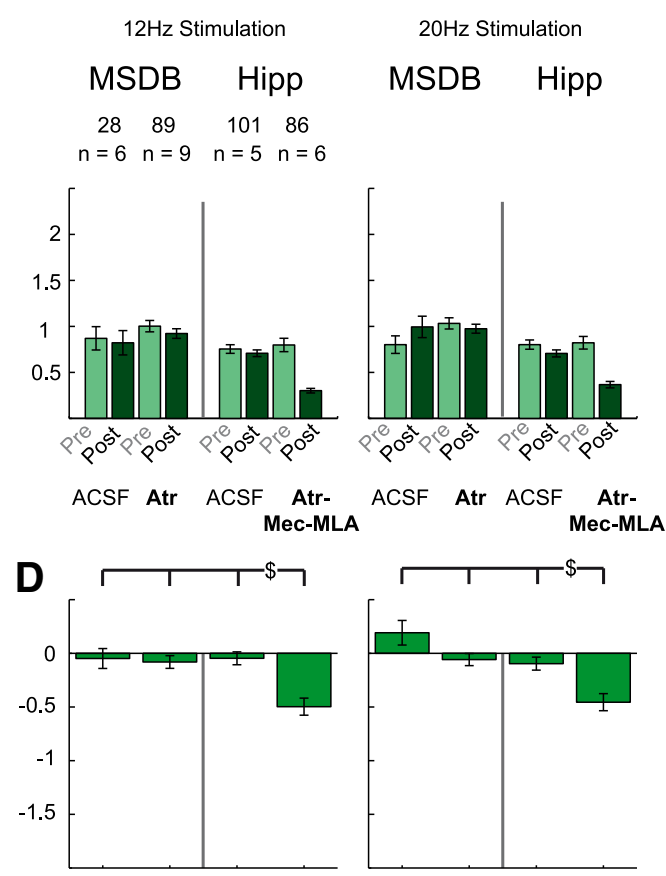

$\mathbf{F}$

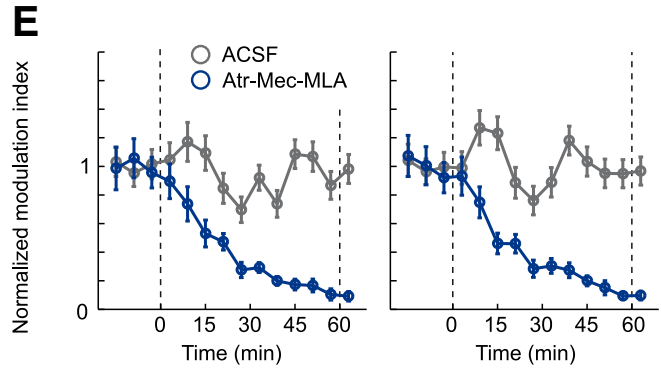

G Focal injections into MSDB
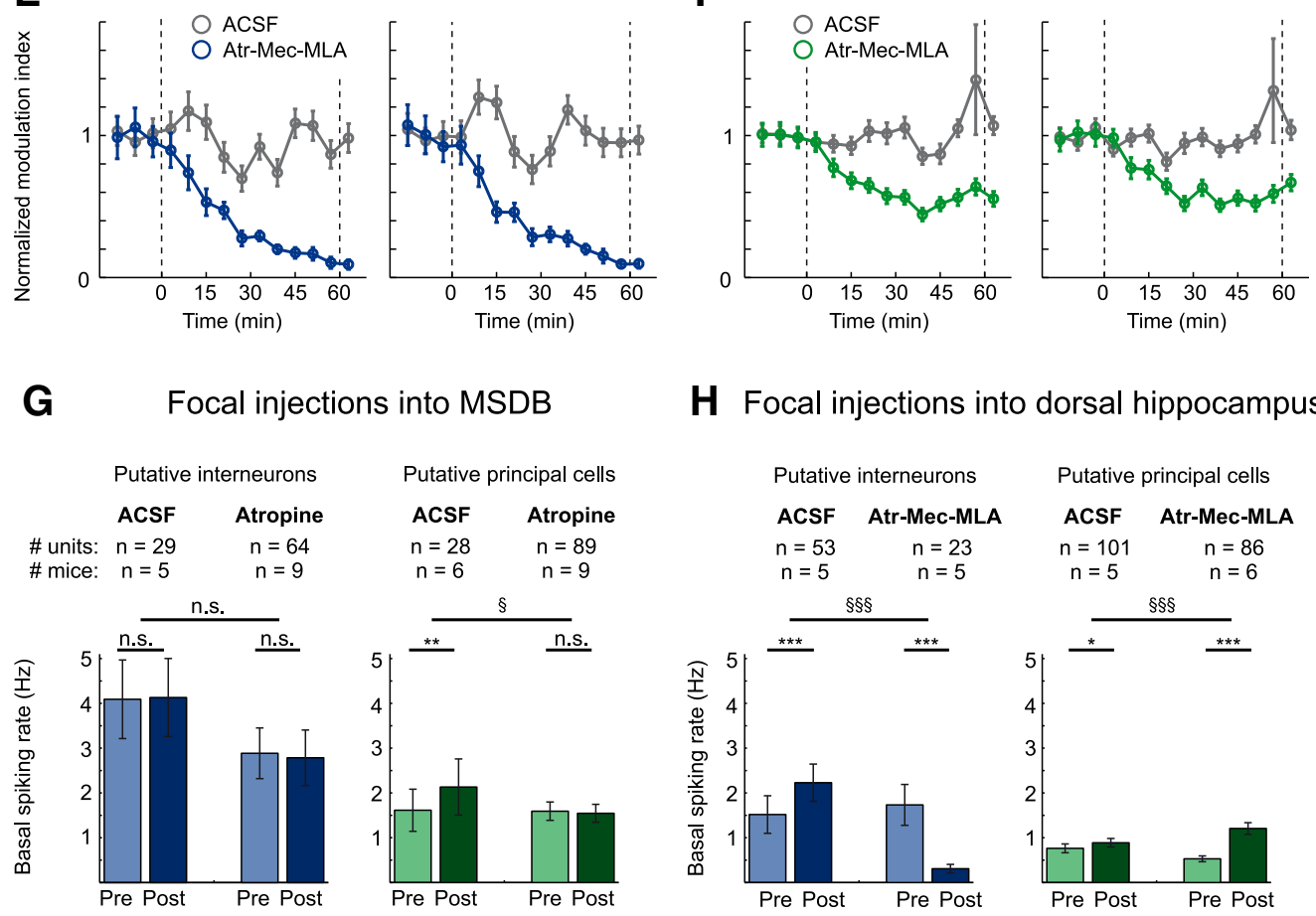

H Focal injections into dorsal hippocampus

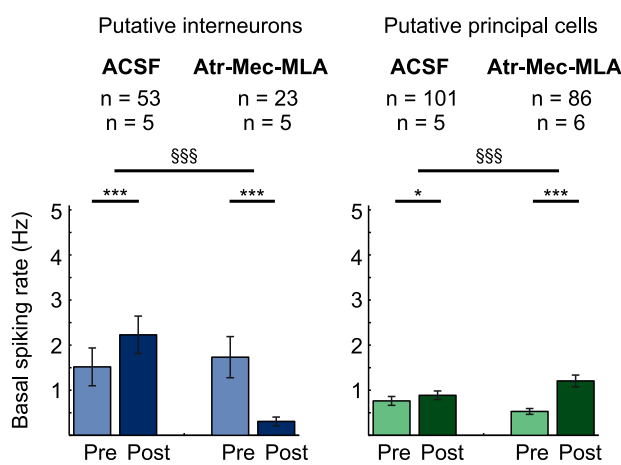

Figure 6. Modulation of neuronal activity in hippocampal area CA3 by cholinergic MSDB neurons is mediated via direct septo-hippocampal projections. A, B, Focal injections of atropine (Atr), 7.2 $\mathrm{mm}$, into the MSDB had no effect, whereas focal injections of the cholinergic blocker mixture containing Atr, $7.2 \mathrm{~mm}, \mathrm{Mec}, 10 \mathrm{~mm}$, and MLA, $20 \mu \mathrm{m}$ into the dorsal hippocampus strongly reduced stimulation-induced modulation of interneuron spiking rates $(\boldsymbol{A})$ and principal cell firing rates $(\boldsymbol{B})$. Data represent mean \pm SEM of modulation indices of single units before and after focal injection of either ACSF or blocker into either the MSDB or the dorsal hippocampus (see $\boldsymbol{A}$ and $\boldsymbol{B}$ for number of analyzed units and mice). $\boldsymbol{C}, \boldsymbol{D}$, Difference between modulation indices of the post- and pre-conditions for every post versus pre pair shown in $\boldsymbol{A}$ and $\boldsymbol{B}$. Frequency of light stimulation was 12 or $20 \mathrm{~Hz}$ as indicated $(\$ p<0.05$ for difference between groups, two-way ANOVA followed by Tukey-Kramer post hoc test). $\boldsymbol{E}, \boldsymbol{F}$, Onset of the effects of blocker injection into the hippocampus. Modulation index was determined as in $\boldsymbol{A}$ and $\boldsymbol{B}$ for 6 min time bins. The onset and offset of blocker injections are indicated with dashed lines. $\boldsymbol{E}$, Interneurons. $\boldsymbol{F}$, Principal neurons. Control experiments with ACSF injections are shown in gray, experiments with hippocampal blocker injections in blue or green, data are represented as mean \pm SEM for the same neurons as in $\boldsymbol{A}-\boldsymbol{D}$. G, Focal injections of ACSF or Atr into the MSDB did not affect basal spiking rates of hippocampal putative interneurons (left). For putative principal cells (right), basal spiking rates were not affected by Atr and even slightly increased after ACSF injection. $\boldsymbol{H}$, In contrast, focal injections of the cholinergic blocker mixture Atr-Mec-MLA strongly reduced basal spiking rates of putative interneurons (left), but strongly increased basal spiking rates of putative principal cells (right). ACSF injections only slightly increased basal spiking rates for both putative interneurons and principal cells. n.s., Not significant. ${ }^{*} p<0.05,{ }^{* *} p<0.01,{ }^{* * *} p<0.001$, Wilcoxon signed-rank test for comparison between preapplication and postapplication conditions; $\S p<0.05$, $\S \S p<0.001$, Mann-Whitney $U$ test for comparison between groups). See $\boldsymbol{G}$ and $\boldsymbol{H}$ for numbers of analyzed units and mice, $3-10$ trials per condition and mouse. 
Modulation of hippocampal neuronal activity by cholinergic MSDB neurons is mediated by direct septohippocampal projections

We next assessed how relevant direct versus indirect MSDB projections to the hippocampus are for the observed inhibition of principal neuron activity (Fig. 2). We measured how optogenetic stimulation of $\mathrm{ChAT}^{+}$MSDB neurons modulates the firing rate of hippocampal neurons in animals that received either focal injections of atropine into the MSDB or injections of a cholinergic blocker mixture (Fig. 3) into the hippocampus. As before, ACSFinjected animals were used as controls.

To quantify the effect on population spiking rate, we calculated a modulation index (see Materials and Methods) of single unit spiking rate modulation for each unit (Fig. $6 A, B$ ). This allows quantifying the effect of ACSF control or blocker injection at the population level via calculation of the delta modulation index; that is, the difference between the modulation indices before and after injection for each cell (Fig. 6C,D). Therefore, at the population level, a mean delta modulation index of zero means no change in spiking rate modulation, whereas a negative mean delta modulation index indicates a decrease of spiking rate modulation.

Two-way ANOVA was performed on the delta modulation indices with the injection site (MSDB vs hippocampus) as one factor and the drug (ACSF vs blocker) as the other factor (Fig. 6C,D). We found a significant main effect of both site and drug for both 12 and $20 \mathrm{~Hz}$ stimulation conditions for putative interneurons $\left(F_{\text {Site }(1,165)}=21.20, p<0.0001\right.$, $F_{\operatorname{Drug}(1,165)}=13.40, p=0.0003$ for $12 \mathrm{~Hz}$ stimulation; $F_{\text {Site }(1,165)}=17.03, p=$ $0.0001, F_{\operatorname{Drug}(1,165)}=17.96, p<0.0001$ for $20 \mathrm{~Hz}$ stimulation) as well as principal cells $\left(F_{\text {Site }(1,300)}=6.50\right.$, $p=0.0113, F_{\operatorname{Drug}(1,300)}=8.85, p=0.0032$ for $12 \mathrm{~Hz}$ stimulation; $F_{\text {Site }(1,300)}=17.46, p<0.0001, F_{\operatorname{Drug}(1,300)}=13.81, p=0.0002$ for $20 \mathrm{~Hz}$ stimulation). There was a significant interaction between site and drug for interneurons under both stimulation conditions $\left(F_{\text {Site }{ }^{*} \operatorname{Drug}(1,165)}=15.84, p=0.0001\right.$ and $F_{\text {Site }{ }^{*} \operatorname{Drug}(1,165)}=11.70$, $p=0.0008$ for 12 and $20 \mathrm{~Hz}$ stimulation, respectively) and for principal cells for the $12 \mathrm{~Hz}$ stimulation condition only $\left(F_{\text {Site }^{*} \operatorname{Drug}(1,300)}=6.62, p=0.0106\right.$ and $F_{\text {Site }^{*} \operatorname{Drug}(1,300)}=0.44, p=$ 0.5081 for 12 and $20 \mathrm{~Hz}$ stimulation conditions, respectively). Whereas focal atropine injection into the MSDB had no effects on single unit modulation ( $p>0.05$, Tukey-Kramer post hoc test), focal injection of a mixture of atropine, Mec, and MLA into the hippocampus abolished spiking rate modulation $(p<$ 0.05, Tukey-Kramer post hoc test) of putative interneurons for both stimulation conditions (Fig. 6C) and strongly reduced spiking rate modulation of putative principal cells, again under both stimulation conditions (Fig. 6D). The onset of the

A

B

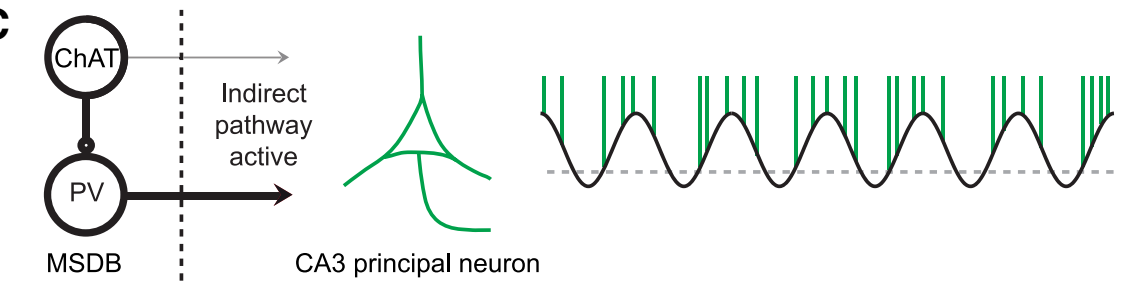

Figure 7. Schematic drawing depicting how the synergy of direct and indirect cholinergic septo-hippocampal pathways may coordinate the firing of principal cells in hippocampal subfield CA3. The solid black line indicates the membrane potential of a representative CA3

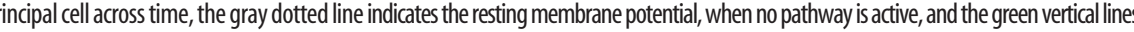
作 of the majority of CA3 principal cells, which results in increased spiking activity. D, The synergistic action of both the direct and indirect cholinergic septo-hippocampal pathways results in reduced but phase-coupled spiking activity.

effects of blocker injections into the hippocampus was plotted by quantifying the modulation index in $6 \mathrm{~min}$ bins and showed a clear onset of the effect within $10 \mathrm{~min}$ of drug application (Fig. 6E, F; time to reach $50 \%$ of the effect obtained with exponential fitting for interneurons 14.1 min after beginning the first injection; for principal neurons $11.7 \mathrm{~min}$ after beginning the first injection, $20 \mathrm{~Hz}$ stimulation). These results suggest that, in contrast to theta generation, modulation of hippocampal unit activity by cholinergic MSDB neurons requires direct septo-hippocampal projections, not a septal relay.

We have also determined the effects of blocker injections on basal discharge rates. Injection of cholinergic blockers into the MSDB did not affect basal firing rates of interneurons or pyramidal neurons (Fig. 6G), but hippocampal injections reduced interneuron firing and increased pyramidal cell firing significantly (Fig. $6 H$ ). 

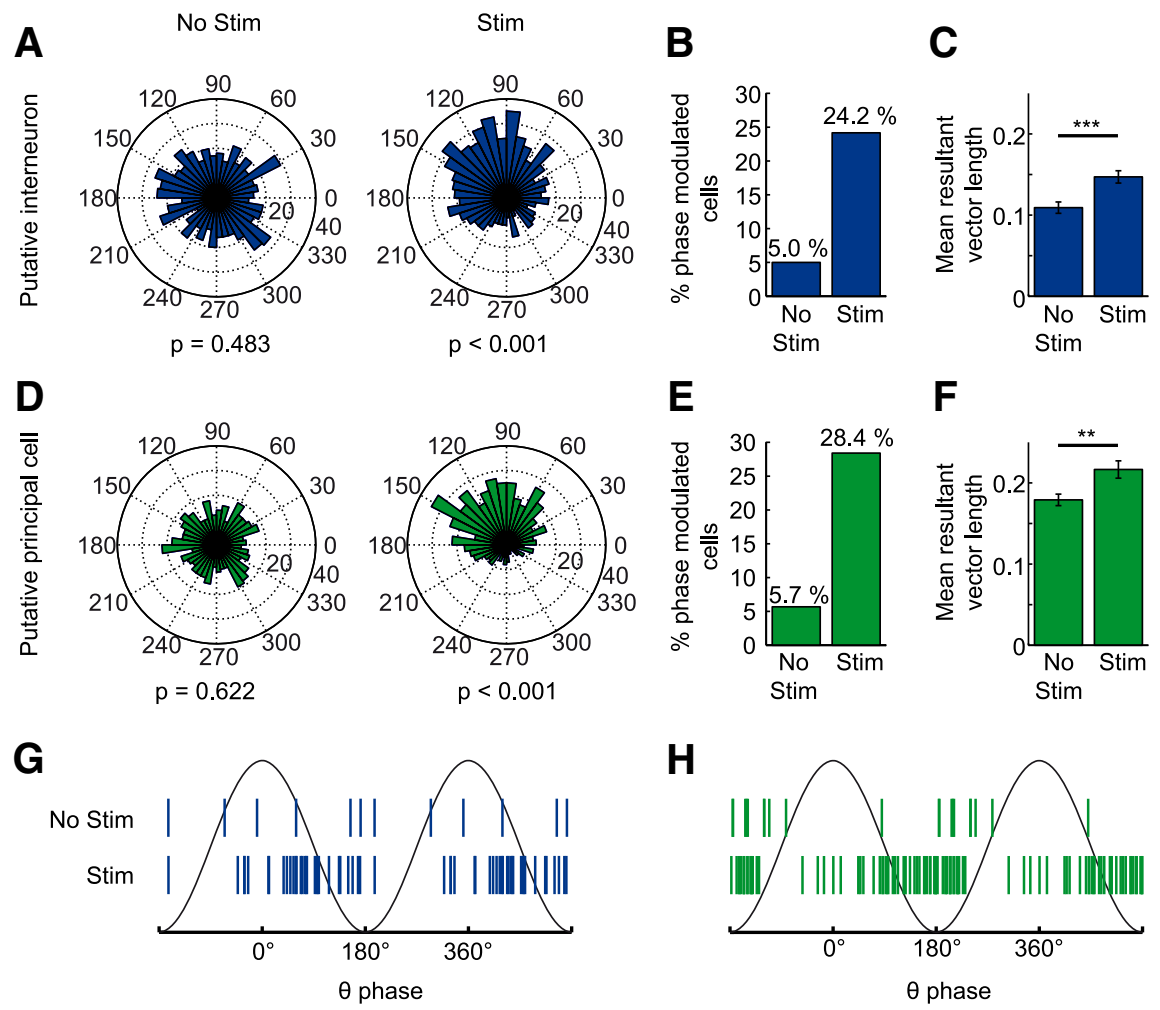

Figure 8. Stimulation of cholinergic MSDB neurons increased spike-phase coupling in area CA3 of the dorsal hippocampus. $A, D$ Spike phase distribution of a single putative interneuron $(\boldsymbol{A})$ or principal cell $(\boldsymbol{D})$ during the baseline (No Stim, left) or stimulation (Stim, right) period. $\boldsymbol{B}, \boldsymbol{E}$, The number of putative interneurons $(\boldsymbol{B})$ and putative principal cells $(\boldsymbol{E})$ that fired significantly phase coupled ( $p<0.05$, Kuiper's test) to the local theta rhythm increased during optogenetic stimulation from $6-29$ (from a total of 120 putative interneurons recorded from 22 mice) and from $10-50$ (from a total of 176 putative principal cells recorded from 24 mice), respectively. Spike numbers of baseline and stimulation conditions were matched by random spike deletion. $\boldsymbol{C}, \boldsymbol{F}$, The mean resultant vector length averaged across putative interneurons $(\boldsymbol{C})$ and putative principal cells $(\boldsymbol{F})$ increased significantly with respect to baseline during the stimulation periods (bar graphs show mean $\pm \mathrm{SEM}$, ${ }^{* *} p<0.01,{ }^{* * *} p<0.001$, Wilcoxon signed-rank test). $\boldsymbol{G}, \boldsymbol{H}$, Mean resultant vector angles of significantly theta-phase-locked putative interneurons $(\boldsymbol{G})$ and putative principal cells $(\boldsymbol{H})$. Note that spiking of putative interneurons clusters around the descending phase, whereas spiking of putative principal cells clusters around the trough of the local theta rhythm.

\section{Cholinergic stimulation increases coupling of hippocampal neuronal firing to theta phase}

So far, these results show that cholinergic septal neurons induce theta synchronization, but at the same time also cause a reduction in principal neuron firing via direct septo-hippocampal projections. We considered the purpose of this dual effect and hypothesized that increasing rhythmic synaptic inputs while simultaneously hyperpolarizing the target population would lead to a more constrained action potential output that is more strictly related to the phase of ongoing theta activity (see Fig. 7 for schematic diagram). We tested this hypothesis by first examining interneuron and principal cell firing with respect to theta phase coupling (Fig. $8 A, D$ ). We used Kuiper's test to identify units with significant phase coupling $(\alpha=0.05)$ during baseline and stimulation periods ( $p$-values indicated for a representative interneuron and pyramidal cell in Fig. $8 A, D$, respectively). The number of both principal cells and interneurons with significant theta phase coupling increased during stimulation (Fig. $8 B, E$ ). To further analyze phase coupling at the population level, we determined the length of the mean resultant vector for each unit. This measure also revealed significantly increased phase coupling both for interneurons (Fig. 8C; $p<0.001, n=120$ from 22 mice, Wilcoxon signed-rank test) and principal cells (Fig. $8 F, p<0.01, n=176$ from 24 mice, Wilcoxon signed-rank test). When considering the phase of the mean resultant vectors only for the phase-coupled units, a preferential phase coupling was observed for interneurons around the descending phase of theta $\left(77 \pm 56^{\circ}\right.$, mean \pm SD; Fig. $\left.8 G\right)$ and for principal cells around the theta trough $\left(156 \pm 59^{\circ}\right.$, mean $\pm \mathrm{SD}$; Fig. $\left.8 H\right)$.

\section{Discussion}

Our findings demonstrate that $\mathrm{ACh}$ release from MSDB neurons has two anatomically and functionally separable effects that act synergistically to make pyramidal neuron firing more precisely coupled to the theta oscillatory phase. First, MSDB cholinergic neurons mediate a sustained increase in hippocampal theta oscillations via an intraseptal relay. Second, direct cholinergic projections from the MSDB to the hippocampus reduce the firing of principal neurons, whereas interneurons are activated.

Our first finding was that optogenetic stimulation of MSDB cholinergic neurons induces hippocampal theta oscillations with a relatively delayed onset. In addition, we found that changing the frequency of cholinergic stimulation led to only small changes in theta frequency $(\sim 1$ $\mathrm{Hz}$ for a $>10$-fold change in stimulation frequency). Both findings are not surprising for effects mediated by metabotropic receptors via a slow second-messenger cascade. Similar effects have been observed recently in anesthetized mice (Vandecasteele et al., 2014). In freely moving mice, increases in theta power were less pronounced, likely due to a higher ACh tone in foraging or ambulatory animals, and seemed to be more related to a suppression of adjacent frequency bands (Vandecasteele et al., 2014). A consistent finding in our experiments was the suppression of frequency bands adjacent to the theta peak. Notably, slow oscillations between 1 and $3 \mathrm{~Hz}$ were suppressed, similar to results obtained in visual cortex during stimulation of basal forebrain cholinergic neurons (Pinto et al., 2013).

A second finding of this study was that CA3 principal neuron activity is strongly inhibited by activation of MSDB cholinergic neurons, whereas interneurons are activated. This finding is in good agreement with the recent description of a reduction in CA3 sharp wave ripple oscillations by optogenetic stimulation of MSDB cholinergic neurons (Vandecasteele et al., 2014).

We next examined the neuronal circuits underlying these two effects: theta induction and inhibition of CA3 pyramidal firing. We found that blocking MSDB muscarinic ACh receptors abolishes optogenetically induced hippocampal theta oscillations, indicating the necessity of a septal relay for theta induction. Indeed, in vitro experiments showed that cholinergic activation causes long-lasting depolarization of putative $\mathrm{PV}^{+}$neurons, in agreement with anatomical data showing that noncholinergic MSDB neurons are contacted by putative cholinergic terminals (Bialowas and Frotscher, 1987; Leranth and Frotscher, 1989). More- 
over, we demonstrate that $\mathrm{PV}^{+}$MSDB neurons are capable of precise synchronization of hippocampal networks. $\mathrm{PV}^{+} \mathrm{MSDB}$ neurons selectively innervate hippocampal interneurons and have long been suggested to be important for hippocampal theta rhythmicity via disinhibition of principal cells (Freund and Antal, 1988; Serafin et al., 1996; Tóth et al., 1997; Hangya et al., 2009; Wulff et al., 2009).

Cumulatively, these data suggest that cholinergic MSDB neurons recruit $\mathrm{PV}^{+}$and perhaps other neurons within the MSDB, which then mediate hippocampal theta synchronization. This is consistent with the finding that $\mathrm{PV}^{+}$neurons in the MSDB pace hippocampal theta oscillations (Varga et al., 2008; Hangya et al., 2009; Huh et al., 2010). These results are also consistent with the inhibition of theta oscillations by focal atropine injection into the medial septum (Kramis et al., 1975). Conversely, activating MSDB neurons by intraseptal infusion of muscarinic agonists in behaving rats causes continuous theta field activity, confirming that intraseptal cholinergic stimulation is not only necessary, but also sufficient for the induction of hippocampal theta oscillations (Lawson and Bland, 1993). Importantly, hippocampal application of cholinergic agonists in vitro is also capable of eliciting theta-like oscillations (Konopacki et al., 1987; Kowalczyk et al., 2013). It is thus important to note that hippocampal networks must also have an autonomous capability to generate theta-like activity without the medial septum. However, theta pacing by the medial septum requires an intraseptal relay.

Importantly, the inhibition of principal cells and the recruitment of interneurons were unaffected by cholinergic antagonists injected into the MSDB, indicating that they do not require a septal relay. Therefore, anatomically separable pathways are responsible for both inducing theta oscillations and reducing firing rates of CA3 neurons. The specific interneuron types that mediate cholinergic inhibition in the $\mathrm{CA} 3$ region can currently not be further pinpointed on the basis of single unit recordings. In principle, different types of hippocampal interneurons appear to be recruited by ACh release from cholinergic axons, both in vitro (Lawrence et al., 2006; Widmer et al., 2006; Cea-del Rio et al., 2010; Nagode et al., 2011, 2014) and in vivo (Lovett-Barron et al., 2014).

What could the functional purpose be for implementing these two separable effects in CA3 pyramidal neurons? The inhibition of CA3 firing, mediated by the direct cholinergic septohippocampal pathway, confirms a prediction made by an influential model for hippocampal encoding and retrieval (Hasselmo et al., 2002). In this model, hippocampal ACh promotes encoding in a time frame of seconds by inhibiting the $\mathrm{CA} 3$ autoassociative network. Both our results and the inhibition of CA3 sharp waveripples support this idea.

In addition, we found a significantly stronger coupling of CA3 pyramidal cell firing to theta phase during optogenetic stimulation of cholinergic MSDB neurons. This is very likely due largely to the strong enhancement in theta oscillatory activity. Nevertheless, a more precise timing of $\mathrm{CA} 3$ neuron firing might promote plasticity in either the autoassociative CA3 network or in CA3CA1 projections (Pavlides et al., 1988; Hölscher et al., 1997; Orr et al., 2001; Hyman et al., 2003). Such an effect has been observed in the human medial temporal lobe and is predictive of subsequent memory performance (Rutishauser et al., 2010). In monkeys, phase locking of single unit activity was observed in the cortex during working memory tasks and this is likewise predictive of memory performance (Liebe et al., 2012). It should be noted, however, that these conclusions, in particular those related to spike-phase synchronization, have to be tempered by the fact that these data were obtained in anesthetized animals, in which principal and interneuron discharge rates are modulated by the anesthetic agent. Experiments in awake animals would be required to determine how the indirect and direct pathways are recruited in behaviorally relevant situations in vivo.

In summary, we have revealed cholinergic network motifs that act synergistically to structure the firing of hippocampal neurons temporally. These circuits may be relevant for information encoding, when cholinergic tone is increased during exploratory behavior and novelty experience (Aloisi et al., 1997; Bianchi et al., 2003).

\section{References}

Aloisi AM, Casamenti F, Scali C, Pepeu G, Carli G (1997) Effects of novelty, pain and stress on hippocampal extracellular acetylcholine levels in male rats. Brain Res 748:219-226. CrossRef Medline

Alreja M, Wu M, Liu W, Atkins JB, Leranth C, Shanabrough M (2000) Muscarinic tone sustains impulse flow in the septohippocampal GABA but not cholinergic pathway: implications for learning and memory. J Neurosci 20:8103-8110. Medline

Andersen P, Bland HB, Myhrer T, Schwartzkroin PA (1979) Septohippocampal pathway necessary for dentate theta production. Brain Res 165:13-22. CrossRef Medline

Anzalone S, Roland J, Vogt B, Savage L (2009) Acetylcholine efflux from retrosplenial areas and hippocampal sectors during maze exploration. Behav Brain Res 201:272-278. CrossRef Medline

Bassant MH, Apartis E, Jazat-Poindessous FR, Wiley RG, Lamour YA (1995) Selective immunolesion of the basal forebrain cholinergic neurons: effects on hippocampal activity during sleep and wakefulness in the rat. Neurodegeneration 4:61-70. CrossRef Medline

Berger-Sweeney J, Stearns NA, Murg SL, Floerke-Nashner LR, Lappi DA, Baxter MG (2001) Selective immunolesions of cholinergic neurons in mice: effects on neuroanatomy, neurochemistry, and behavior. J Neurosci 21:8164-8173. Medline

Bialowas J, Frotscher M (1987) Choline acetyltransferase-immunoreactive neurons and terminals in the rat septal complex: a combined light and electron microscopic study. J Comp Neurol 259:298-307. CrossRef Medline

Bianchi L, Ballini C, Colivicchi MA, Della Corte L, Giovannini MG, Pepeu G (2003) Investigation on acetylcholine, aspartate, glutamate and GABA extracellular levels from ventral hippocampus during repeated exploratory activity in the rat. Neurochem Res 28:565-573. CrossRef Medline

Bland BH (1986) The physiology and pharmacology of hippocampal formation theta rhythms. Prog Neurobiol 26:1-54. CrossRef Medline

Buzsáki G (2002) Theta oscillations in the hippocampus. Neuron 33:325340. CrossRef Medline

Buzsáki G, Moser EI (2013) Memory, navigation and theta rhythm in the hippocampal-entorhinal system. Nat Neurosci 16:130-138. CrossRef Medline

Cai L, Gibbs RB, Johnson DA (2012) Recognition of novel objects and their location in rats with selective cholinergic lesion of the medial septum. Neurosci Lett 506:261-265. CrossRef Medline

Cea-del Rio CA, Lawrence JJ, Tricoire L, Erdelyi F, Szabo G, McBain CJ (2010) M3 muscarinic acetylcholine receptor expression confers differential cholinergic modulation to neurochemically distinct hippocampal basket cell subtypes. J Neurosci 30:6011-6024. CrossRef Medline

Chrobak JJ, Stackman RW, Walsh TJ (1989) Intraseptal administration of muscimol produces dose-dependent memory impairments in the rat. Behav Neural Biol 52:357-369. CrossRef Medline

Csicsvari J, Hirase H, Czurko A, Buzsáki G (1998) Reliability and state dependence of pyramidal cell-interneuron synapses in the hippocampus: an ensemble approach in the behaving rat. Neuron 21:179-189. CrossRef Medline

Donovick PJ (1968) Effects of localized septal lesions on hippocampal EEG activity and behavior in rats. J Comp Physiol Psychol 66:569-578. CrossRef Medline

Freund TF, Antal M (1988) GABA-containing neurons in the septum control inhibitory interneurons in the hippocampus. Nature 336:170-173. CrossRef Medline

Giovannini MG, Rakovska A, Benton RS, Pazzagli M, Bianchi L, Pepeu G (2001) Effects of novelty and habituation on acetylcholine, GABA, and 
glutamate release from the frontal cortex and hippocampus of freely moving rats. Neuroscience 106:43-53. CrossRef Medline

Givens B, Olton DS (1994) Local modulation of basal forebrain: effects on working and reference memory. J Neurosci 14:3578-3587. Medline

Gorelova N, Reiner PB (1996) Role of the afterhyperpolarization in control of discharge properties of septal cholinergic neurons in vitro. J Neurophysiol 75:695-706. Medline

Grandchamp R, Delorme A (2011) Single-trial normalization for eventrelated spectral decomposition reduces sensitivity to noisy trials. Front Psychol 2.

Green JD, Arduini AA (1954) Hippocampal electrical activity in arousal. J Neurophysiol 17:533-557. Medline

Griffith WH, Matthews RT (1986) Electrophysiology of AChE-positive neurons in basal forebrain slices. Neurosci Lett 71:169-174. CrossRef Medline

Hangya B, Borhegyi Z, Szilágyi N, Freund TF, Varga V (2009) GABAergic neurons of the medial septum lead the hippocampal network during theta activity. J Neurosci 29:8094-8102. CrossRef Medline

Harris KD, Henze DA, Csicsvari J, Hirase H, Buzsáki G (2000) Accuracy of tetrode spike separation as determined by simultaneous intracellular and extracellular measurements. J Neurophysiol 84:401-414. Medline

Hasselmo ME, Schnell E, Barkai E (1995) Dynamics of learning and recall at excitatory recurrent synapses and cholinergic modulation in rat hippocampal region CA3. J Neurosci 15:5249-5262. Medline

Hasselmo ME, Bodelón C, Wyble BP (2002) A proposed function for hippocampal theta rhythm: separate phases of encoding and retrieval enhance reversal of prior learning. Neural Comput 14:793-817. CrossRef Medline

Hölscher C, Anwyl R, Rowan MJ (1997) Stimulation on the positive phase of hippocampal theta rhythm induces long-term potentiation that can Be depotentiated by stimulation on the negative phase in area CA1 in vivo. J Neurosci 17:6470-6477. Medline

Huh CY, Goutagny R, Williams S (2010) Glutamatergic neurons of the mouse medial septum and diagonal band of Broca synaptically drive hippocampal pyramidal cells: relevance for hippocampal theta rhythm. J Neurosci 30:15951-15961. CrossRef Medline

Hyman JM, Wyble BP, Goyal V, Rossi CA, Hasselmo ME (2003) Stimulation in hippocampal region CA1 in behaving rats yields long-term potentiation when delivered to the peak of theta and long-term depression when delivered to the trough. J Neurosci 23:11725-11731. Medline

Ji D, Dani JA (2000) Inhibition and disinhibition of pyramidal neurons by activation of nicotinic receptors on hippocampal interneurons. J Neurophysiol 83:2682-2690. Medline

Konopacki J, MacIver MB, Bland BH, Roth SH (1987) Carbachol-induced EEG "theta" activity in hippocampal brain slices. Brain Res 405:196-198. CrossRef Medline

Kowalczyk T, Bocian R, Konopacki J (2013) The generation of theta rhythm in hippocampal formation maintained in vitro. Eur J Neurosci 37:679699. CrossRef Medline

Kramis R, Vanderwolf CH, Bland BH (1975) Two types of hippocampal rhythmical slow activity in both the rabbit and the rat: relations to behavior and effects of atropine, diethyl ether, urethane, and pentobarbital. Exp Neurol 49:58-85. CrossRef Medline

Lawrence JJ, Statland JM, Grinspan ZM, McBain CJ (2006) Cell typespecific dependence of muscarinic signalling in mouse hippocampal stratum oriens interneurones. J Physiol 570:595-610. CrossRef Medline

Lawson VH, Bland BH (1993) The role of the septohippocampal pathway in the regulation of hippocampal field activity and behavior: analysis by the intraseptal microinfusion of carbachol, atropine, and procaine. Exp Neurol 120:132-144. CrossRef Medline

Lee MG, Chrobak JJ, Sik A, Wiley RG, Buzsáki G (1994) Hippocampal theta activity following selective lesion of the septal cholinergic system. Neuroscience 62:1033-1047. CrossRef Medline

Leranth C, Frotscher M (1989) Organization of the septal region in the rat brain: cholinergic-GABAergic interconnections and the termination of hippocampo-septal fibers. J Comp Neurol 289:304-314. CrossRef Medline

Liebe S, Hoerzer GM, Logothetis NK, Rainer G (2012) Theta coupling between V4 and prefrontal cortex predicts visual short-term memory performance. Nat Neurosci 15:456-462, S1-S2. Medline

Lovett-Barron M, Kaifosh P, Kheirbek MA, Danielson N, Zaremba JD, Reardon TR, Turi GF, Hen R, Zemelman BV, Losonczy A (2014) Dendritic inhibition in the hippocampus supports fear learning. Science 343:857863. CrossRef Medline

Markram H, Segal M (1990) Electrophysiological characteristics of cholinergic and non-cholinergic neurons in the rat medial septum-diagonal band complex. Brain Res 513:171-174. CrossRef Medline

Mesulam MM, Mufson EJ, Wainer BH, Levey AI (1983) Central cholinergic pathways in the rat: an overview based on an alternative nomenclature (Ch1-Ch6). Neuroscience 10:1185-1201. CrossRef Medline

Moreau PH, Cosquer B, Jeltsch H, Cassel JC, Mathis C (2008) Neuroanatomical and behavioral effects of a novel version of the cholinergic immunotoxin mu p75-saporin in mice. Hippocampus 18:610-622. CrossRef Medline

Nagel G, Brauner M, Liewald JF, Adeishvili N, Bamberg E, Gottschalk A (2005) Light activation of channelrhodopsin-2 in excitable cells of Caenorhabditis elegans triggers rapid behavioral responses. Curr Biol 15: 2279-2284. CrossRef Medline

Nagode DA, Tang AH, Karson MA, Klugmann M, Alger BE (2011) Optogenetic release of ACh induces rhythmic bursts of perisomatic IPSCs in hippocampus. PLoS One 6:e27691. CrossRef Medline

Nagode DA, Tang AH, Yang K, Alger BE (2014) Optogenetic identification of an intrinsic cholinergically driven inhibitory oscillator sensitive to cannabinoids and opioids in hippocampal CA1. J Physiol 592:103-123. CrossRef Medline

Oostenveld R, Fries P, Maris E, Schoffelen JM (2011) FieldTrip: Open source software for advanced analysis of MEG, EEG, and invasive electrophysiological data. Comput Intell Neurosci 2011:156869. Medline

Orr G, Rao G, Houston FP, McNaughton BL, Barnes CA (2001) Hippocampal synaptic plasticity is modulated by theta rhythm in the fascia dentata of adult and aged freely behaving rats. Hippocampus 11:647-654. CrossRef Medline

Pavlides C, Greenstein YJ, Grudman M, Winson J (1988) Long-term potentiation in the dentate gyrus is induced preferentially on the positive phase of theta-rhythm. Brain Res 439:383-387. CrossRef Medline

Paxinos G, Franklin KBJ (2008) The mouse brain in stereotaxic coordinates, the coronal plates and diagrams, Ed 3. Amsterdam: Academic.

Petsche H, Stumpf C, Gogolak G (1962) The significance of the rabbit's septum as a relay station between the midbrain and the hippocampus. I. The control of hippocampus arousal activity by the septum cells. Electroencephalogr Clin Neurophysiol 14:202-211. CrossRef Medline

Pinto L, Goard MJ, Estandian D, Xu M, Kwan AC, Lee SH, Harrison TC, Feng G, Dan Y (2013) Fast modulation of visual perception by basal forebrain cholinergic neurons. Nat Neurosci 16:1857-1863. CrossRef Medline

Quiroga RQ, Nadasdy Z, Ben-Shaul Y (2004) Unsupervised spike detection and sorting with wavelets and superparamagnetic clustering. Neural Comput 16:1661-1687. CrossRef Medline

Rawlins JN, Feldon J, Gray JA (1979) Septo-hippocampal connections and the hippocampal theta rhythm. Exp Brain Res 37:49-63. CrossRef Medline

Rogers JL, Kesner RP (2003) Cholinergic modulation of the hippocampus during encoding and retrieval. Neurobiol Learn Mem 80:332-342. CrossRef Medline

Rutishauser U, Ross IB, Mamelak AN, Schuman EM (2010) Human memory strength is predicted by theta-frequency phase-locking of single neurons. Nature 464:903-907. CrossRef Medline

Serafin M, Williams S, Khateb A, Fort P, Mühlethaler M (1996) Rhythmic firing of medial septum non-cholinergic neurons. Neuroscience 75:671675. CrossRef Medline

Sotty F, Danik M, Manseau F, Laplante F, Quirion R, Williams S (2003) Distinct electrophysiological properties of glutamatergic, cholinergic and GABAergic rat septohippocampal neurons: novel implications for hippocampal rhythmicity. J Physiol 551:927-943. CrossRef Medline

Stanley EM, Wilson MA, Fadel JR (2012) Hippocampal neurotransmitter efflux during one-trial novel object recognition in rats. Neurosci Lett 511:38-42. CrossRef Medline

Stewart M, Fox SE (1990) Do septal neurons pace the hippocampal theta rhythm? Trends Neurosci 13:163-168. CrossRef Medline

Stumpf C, Petsche H, Gogolak G (1962) The significance of the rabbit's septum as a relay station between the midbrain and the hippocampus. II. The differential influence of drugs upon both the septal cell firing pattern and the hippocampus theta activity. Electroencephalogr Clin Neurophysiol 14:212-219. CrossRef Medline

Tóth K, Freund TF, Miles R (1997) Disinhibition of rat hippocampal pyra- 
midal cells by GABAergic afferents from the septum. J Physiol 500:463474. CrossRef Medline

van Loo KM, Schaub C, Pernhorst K, Yaari Y, Beck H, Schoch S, Becker AJ (2012) Transcriptional regulation of T-type calcium channel $\mathrm{Ca}_{\mathrm{v}} 3.2$ : bidirectionality by early growth response 1 (Egr1) and repressor element 1 (RE-1) protein-silencing transcription factor (REST). J Biol Chem 287: 15489-15501. CrossRef Medline

Vandecasteele M, Varga V, Berényi A, Papp E, Barthó P, Venance L, Freund TF, Buzsáki G (2014) Optogenetic activation of septal cholinergic neurons suppresses sharp wave ripples and enhances theta oscillations in the hippocampus. Proc Natl Acad Sci U S A

Varga V, Hangya B, Kránitz K, Ludányi A, Zemankovics R, Katona I, Shigemoto R, Freund TF, BorhegyiZ (2008) The presence of pacemaker HCN channels identifies theta rhythmic GABAergic neurons in the medial septum. J Physiol 586:3893-3915. CrossRef Medline

Widmer H, Ferrigan L, Davies CH, Cobb SR (2006) Evoked slow muscarinic acetylcholinergic synaptic potentials in rat hippocampal interneurons. Hippocampus 16:617-628. CrossRef Medline

Wulff P, Ponomarenko AA, Bartos M, Korotkova TM, Fuchs EC, Bähner F, Both M, Tort AB, Kopell NJ, Wisden W, Monyer H (2009) Hippocampal theta rhythm and its coupling with gamma oscillations require fast inhibition onto parvalbumin-positive interneurons. Proc Natl Acad Sci U S A 106:3561-3566. CrossRef Medline

Yoder RM, Pang KC (2005) Involvement of GABAergic and cholinergic medial septal neurons in hippocampal theta rhythm. Hippocampus 15:381392. CrossRef Medline 